This is a post-peer-review, pre-copyedit version of an article published in Phytochemistry Reviews. The final authenticated version is available online at:

https://doi.org/10.1007/s11101-020-09710-8

\title{
Application of dietary supplements in the prevention of type 2 diabetes-related cardiovascular complications
}

Natural Products in Drug Discovery and Human Health

Lisbon, 28-31 July, 2019

Yannan Jin ${ }^{1}$, Randolph RJ Arroo ${ }^{2 *}$

${ }^{1}$ School of Allied Health Sciences, Faculty of Health \& Life Sciences, De Montfort University, The Gateway, Leicester LE1 9BH, United Kingdom

${ }^{2}$ Leicester School of Pharmacy, Faculty of Health \& Life Sciences, De Montfort University, The Gateway, Leicester LE1 9BH, United Kingdom

* Corresponding Author, Email: rrjarroo@ dmu.ac.uk 


\section{Abstract}

Type 2 diabetes, which accounts for the vast majority of diabetes worldwide is the result of a lowered sensitivity of the insulin receptors, resulting in impaired sugar metabolism is and chronic hyperglycaemia. There is no cure for type 2 diabetes, though some people with prediabetes and diabetes manage to reach and hold normal blood sugar levels, thus avoiding most of the complications that come with chronic hyperglycaemia; this is sometimes referred to as 'reversing diabetes'. A healthy diet, with sufficient amounts of fruits, nuts, and vegetables is positively correlated with maintaining glycaemic control and prevention of diabetes-related complications.

Whereas many different dietary phytochemicals have been considered to play a role in the glycaemic control and in prevention of degenerative diseases, there is currently no consensus on a particular mode of action. In this review, a range of pre-clinical studies and intervention studies, including randomised double-blind, placebo controlled clinical studies, are considered that investigate the role of dietary compounds in the prevention of type 2 diabetesrelated complications. Three generic mechanisms of action can be discerned: compounds that reduce sugar uptake, compounds that restore insulin function, and compounds that attenuate the effects of oxidative stress and chronic inflammation. Particularly the latter has received wide attention in the form of activation of the Nrf2-antioxidant response element signalling pathway by various polyphenolic or triterpenoid compounds. Although individual reports may present models with clear looking signalling cascades, an overall review shows that many biologically active compounds in the human diet are pan assay interference substances that alter several cell functions simultaneously, which makes them less attractive for drug development.

Key words: Flavonoids; oxidative stress; inflammation; pan assay interference substances; homeostasis 


\section{Diabetes}

Diabetes is a metabolic disorder characterised by prolonged high blood sugar levels (hyperglycaemia). Assessment of blood sugar levels is typically done by measuring the level of glucose in small blood samples after overnight fasting (fasting blood sugar); levels less than $100 \mathrm{mg} / \mathrm{dL}(5.6 \mathrm{mM})$ are considered healthy, $100-125 \mathrm{mg} / \mathrm{dL}(5.6-6.9 \mathrm{mM})$ is considered pre-diabetes, and more than $126 \mathrm{mg} / \mathrm{dL}(>7 \mathrm{mM})$ is considered diabetes.

In 2019, 351.7 million people of working age (20-64 years) had diagnosed or undiagnosed diabetes. This number is expected to rise to 417.3 million by 2030 . The largest increase is expected to take place in the regions where economies are moving from low- to middleincome status (Williams et al., 2019)

Type 2 diabetes (T2D), which accounts for the vast majority (around 90\%) of diabetes worldwide (Williams et al., 2019), is the result of a lowered sensitivity of the insulin receptors notably on cells in the liver and muscles. The insulin resistance is often initially compensated by $\beta$-cell hypersecretion of insulin (hyperinsulinaemia); prescription drugs like sulfonylureas work by stimulating $\beta$-cells to more activity. However, in advanced stages the $\beta$-cells, located in the islets of Langerhans of the pancreas, eventually are no longer able to secrete enough insulin (hypoinsulinaemia). Abnormal insulin sensitivity commonly precedes the clinical diagnosis of diabetes by up to 15 years (Zaccardi et al. 2015).

Insulin signalling pathways are triggered by the binding of insulin to the transmembrane insulin receptor. This induces auto-phosphorylation in tyrosine residues of the receptor followed by downstream cascading events which create a suitable binding site for insulin receptor substrate proteins (IRSs), which is then activated via phosphorylation by different insulin-induced kinases such as PKC, SIK2, AKT, S6K1, mTOR, ERK1/2, and ROCK1. Insulin-independent kinases, such as AMPK and GSK3, in turn phosphorylate IRSs and trigger downstream signal transduction. Though the exact pathophysiology of insulin 
resistance is unclear, defects in insulin signal transduction play a prominent role (Yaribeygi et al., 2018). The biguanide metformin (1) (Fig. 1) is commonly prescribed to delay the loss of insulin sensitivity in the liver, muscle, and adipose tissue, but the exact molecular mechanism of this drug is not yet completely understood. Metformin is an analogue of galegine (2), a naturally occurring guanidine found in Galega officinalis L. which was also used to treat diabetes but is now considered obsolete (Bailey \& Day, 2004).<smiles>CN(C)C(=N)NC(=N)N</smiles>

1 - Metformin<smiles>CC(C)=CCNC(=N)N</smiles>

2- Galegine

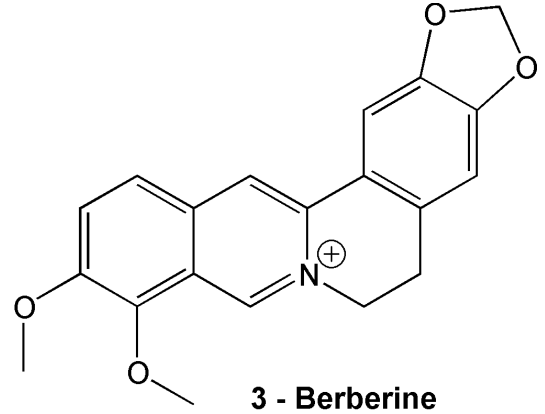

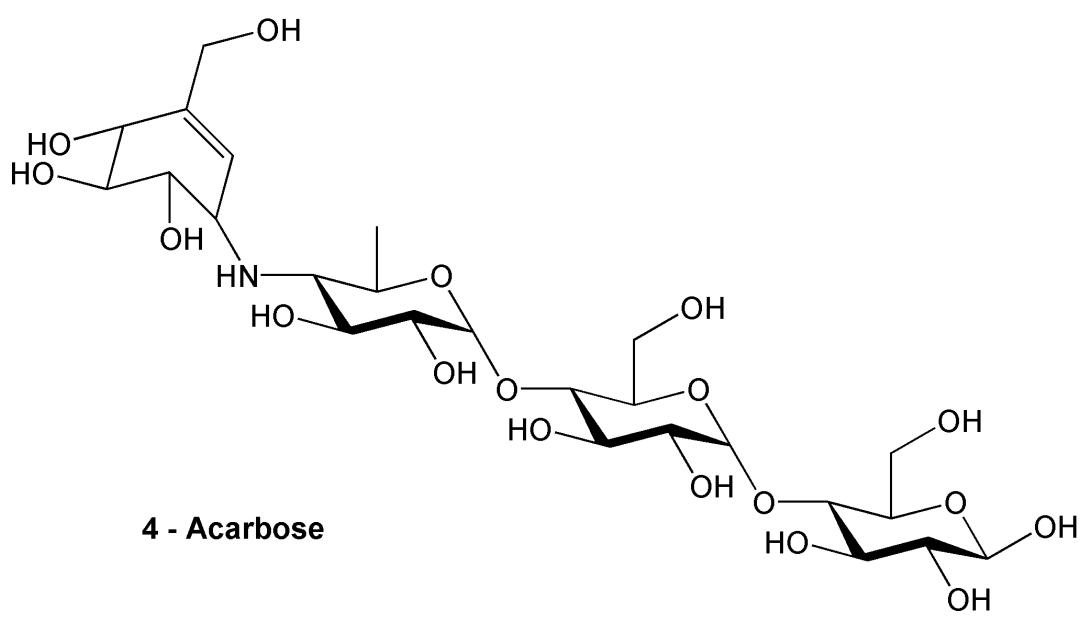

Fig 1: Compounds with known antidiabetic activity

Diabetes is linked with roughly doubling the risk for a wide range of vascular diseases, and data based on a study with 302430 participants are consistent with a causal association, although the causal component or components in this pathway have not yet been identified (Sarwar et al., 2010, Sarwar \& Danesh, 2010). Diabetes is also associated with premature death from infectious diseases, several types of cancer, and degenerative disorders. However, causal links are still unclear. The associations might be due to hyperglycemia or other 
biologic factors such as insulin resistance or hyperinsulinemia, or due to shared risk factors (e.g., obesity) or a combination of these (Seshasai et al., 2011).

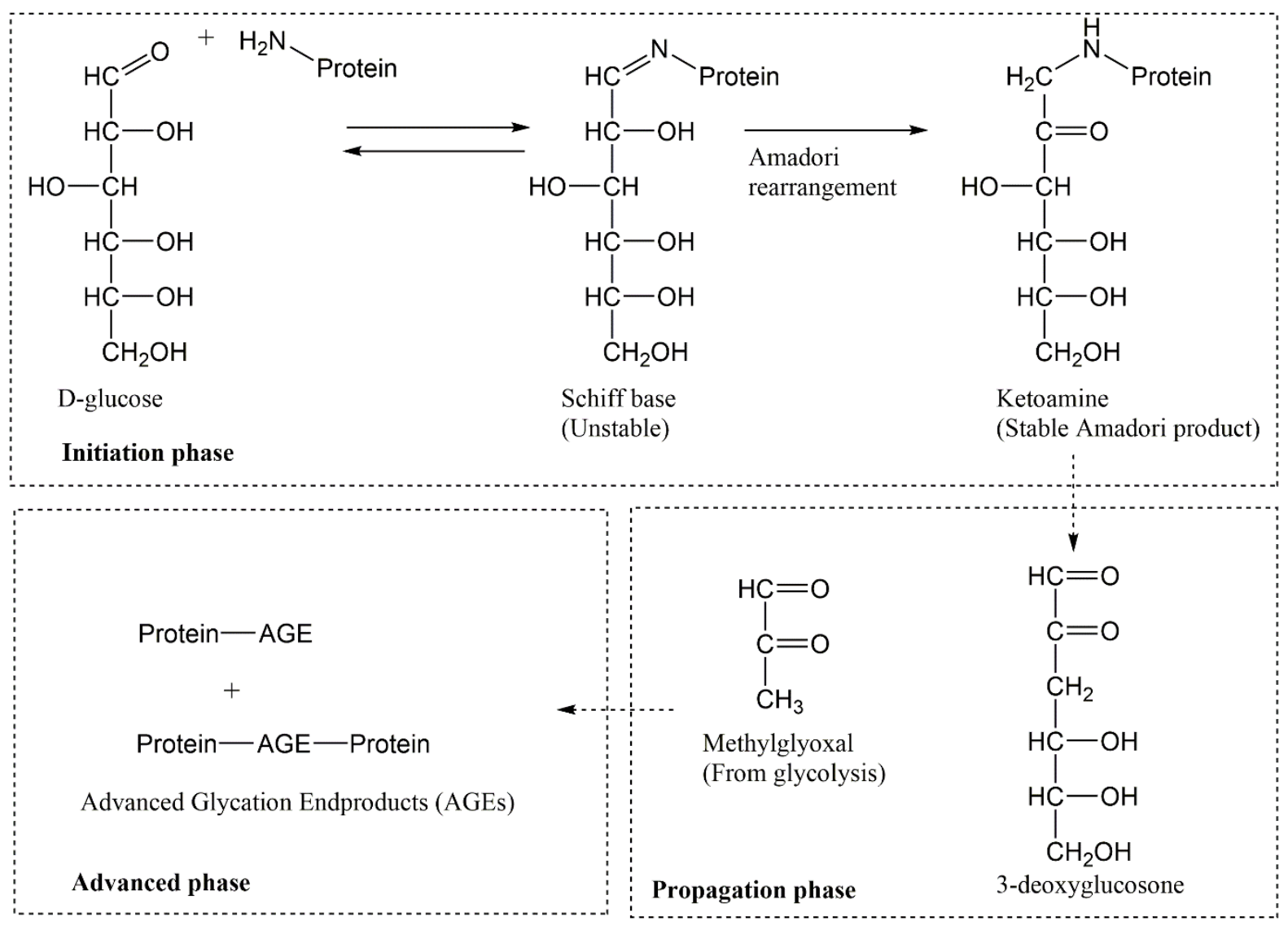

Fig 2: Formation of Advance Glycation Endproducts (AGEs)

Chronic hyperglycaemia can result in a number of complications. High levels of glucose or fructose in the blood plasma can initially result in glycation reaction, i.e. nonenzymatic attachment of a monosaccharide to the $\mathrm{N}$-terminus of a protein or to the amino groups of arginine or lysine residues followed by Amadori rearrangement resulting in the formation of a ketoamine (Fig. 2). Glycation should not be confused with glycosylation, the enzymecontrolled post-transcriptional process that occurs during synthesis of glycoproteins as part of normal healthy physiology. Glycation occurs continuously over the lifetime of the protein, so the concentration of glycated haemoglobin (HbA1c) levels can be used as a measure of the average blood glucose value over a period of time (Welsh et al., 2016). HbA1c levels are a 
measure for blood glucose management, and can be tested every three months - a normal HbA1c target is below $48 \mathrm{mmol} / \mathrm{mol}$ (or $6.5 \%$ on the older measurement scale). People who are at risk of hypoglycemia, or for whom tight blood glucose regulation is not advised, may be advised to keep their HbA1c below $59 \mathrm{mmols} / \mathrm{mol}$ (under $7.5 \%$ in the old percentage units).

After the initiation phase of glycation, a propagation phase starts where Amadori products are degraded resulting in the formation of free radicals and reactive dicarbonyl species, e.g. 3deoxyglucosone. Additional reactive dicarbonyls, e.g. methylglyoxal which is formed as by product of glycolysis, also add to the propagation of glycation. Finally, in the advanced phase, advanced glycation products (AGEs) are formed, and the interaction between AGEs and their receptor, RAGE, is considered to be a main cause of chronic diseases, oxidative stress, and a state of low-grade chronic inflammation (Brownlee 2001; Peyroux \& Sternberg, 2006; Yeh et al., 2017a, 2017b; Fournet et al., 2018). During normal metabolism, methylglyoxal and other reactive aldehydes are detoxified by the glyoxalase system, but chronic hyperglycaemia can eventually overwhelm this detoxification process, resulting in the accumulation of AGEs.

Interaction of AGEs with RAGE on the membrane of cells such as macrophages, mesangial or endothelial cells, pericytes, causes intracellular oxidative stress and activation of nuclear factor NF-kB via activation of the mitogen-activated protein (MAP) kinase signalling pathway

\section{Role of diet}

Occurrence of T2D is correlated with lifestyle and dietary patterns; notably, greater consumption of sugar-rich foods is correlated with increased levels of T2D (Basu et al., 
2013). Although currently there is no cure for T2D, some people with pre-diabetes and diabetes manage to reach and hold normal blood sugar levels, and thus avoid most of the complications that come with prolonged hyperglycaemia; this is sometimes referred to as 'reversing diabetes'. For overweight or obese individuals with T2D, a weight loss of at least 5\% was shown to improve circulating glucose and lipid levels over 12 months (Franz et al., 2015). A 3-year randomized clinical trial followed by 7-years of open-label modified intervention follow-up showed that regular moderate exercise and a healthy diet over a 10year period reduced the absolute risk of getting diabetes by $25.9 \%$ (Herman et al., 2013). Systematic reviews and meta-analyses of dietary patterns have indicated that regular consumption of red meat, processed meat, and sugar-sweetened beverages is linked with an increased incidence of T2D, whereas increased consumption o whole grains, fruits, and dairy is linked with a lowered risk of becoming diabetic (Medina-Remón et al., 2017; Schwingshackl et al., 2017).

Diabetes is a chronic condition, and it takes continuous effort to attain adequate glycemic control amongst diabetic patients. Individuals with T2D are commonly treated with multiplemedication regimens - some to achieve glycemic control, others to treat diabetic complications - to an average of four prescription medications per patient per day. In addition, weight loss is often advised in management of T2D (Gonzalez et al., 2016). Diabetes places a significant self-management burden on affected individuals and families, but available evidence suggests that diabetes among the illnesses with the lowest levels of adequate self-management, especially for regimen aspects involving lifestyle change. Nonadherence to prescription medicines is common, and patients often look to alternative forms of therapy such as herbal medicines (Ezuruike \& Prieto, 2014). Meta analyses of the use of herbal medicines to manage T2D, e.g. berberine (3) from Coptis chinensis Franch ('Huanglian') in Chinese Herbal Medicine, or extracts of bitter gourd (Momordica charantia 
L.) as in Asia, Brazil, and east Africa, have indicated some efficacy, although authors warn for the risk of bias in the included studies (Lan et al., 2015; Peter et al., 2019). More methodologically sound large controlled trials, using standardized preparations, are required to more clearly quantify the therapeutic effect of herbal preparations.

\section{Mechanism studies}

There is a general consensus that a diet rich in fruit, vegetables, and high in fibre is beneficial for maintaining blood sugar levels within reasonable limits, and for slowing down or averting diabetes-related complications. However, there is no canonical vision on any particular dietary compounds that can be considered the main active pharmaceutical ingredient. Neither is there a consensus on any one particular mechanism of action. Rather three generic mechanisms of action can be discerned: compounds that reduce sugar uptake, compounds that restore insulin function, and compounds that attenuate the effects of oxidative stress and chronic inflammation.

The prescription drug acarbose (4) (Glucobay $^{\mathrm{TM}}$, Precose ${ }^{\mathrm{TM}}$, Prandase ${ }^{\mathrm{TM}}$ ) prevents hydrolysis of starches into glucose. Similarly, several dietary flavonoids (5) (Fig. 3) also effectively inhibit the activity of $\alpha$-amylase and $\alpha$-glucosidase (Xiao et al., 2013a,b; Zhu et al., 2020). Acarbose causes adverse effects such as bloating, flatulence, or diarrhoea, and this is often used as a justification to look for natural alternatives. However, arguably any compound that inhibits degradation of complex carbohydrates will result in delivery of these carbohydrates to the colon where they are digested by bacteria, causing gastrointestinal side-effects. Papers on $\alpha$-amylase and $\alpha$-glucosidase inhibitors tend to report results of in vitro enzyme inhibition assays - sometimes backed up by in silico docking studies, but often omit data on in vivo efficacy or side effects of flavonoids or herbal preparations. In a similar fashion, phytic acid 


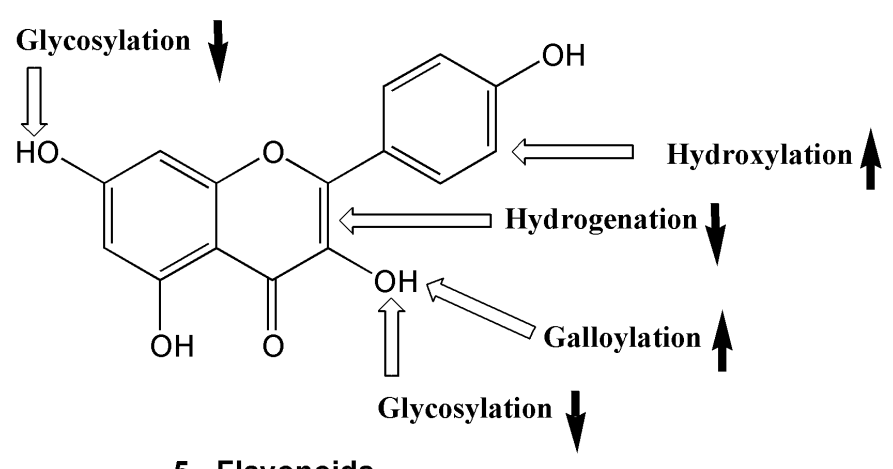

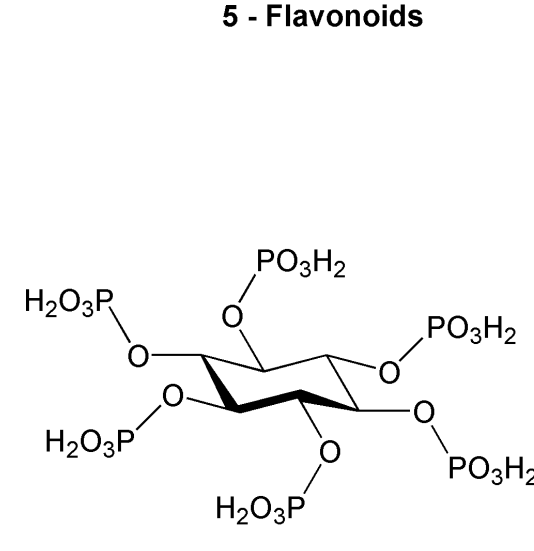

6 - Phytic acid

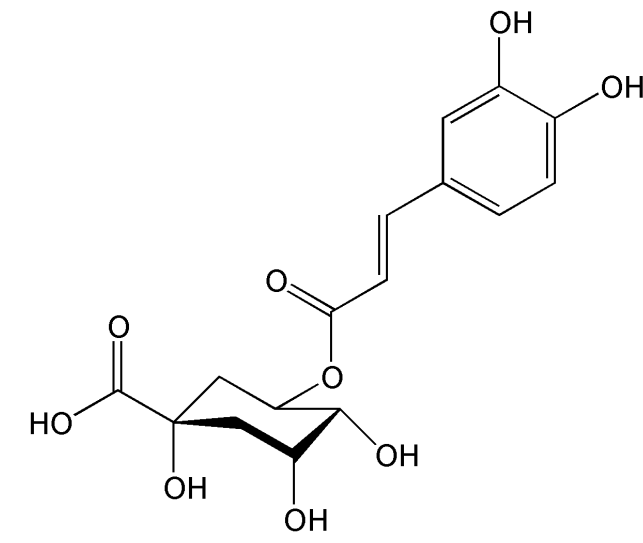

7 - Chlorogenic acid<smiles>COc1ccc(/C=C/C(=O)O)cc1O</smiles>

8 - Ferulic acid

Fig. 3: Inhibitors of carbohydrate digestion and glucose absorption

or phytate (6), normally present in the aleurone layer of cereals though often lost in the milling process, hinders digestion by binding with starch and starch-associated protein (Biskup et al., 2017). Some simple phenolics, e.g. chlorogenic acid (7) and ferulic acid (8) have exhibited the ability to block glucose transporter SGLT1, and thus inhibit glucose absorption from the small intestine and glucose reabsorption in the kidneys (Biskup et al., 2017).

The isoflavone genistein (9) (Fig. 4) enhanced activity of adenylate cyclase activity in a dosedependent way (10nM - $5 \mu \mathrm{M})$ in insulin-secreting murine cell lines INS-1 and MIN6 and in vitro cultured mouse pancreatic islets. The resulting rise in intracellular cAMP activated protein kinase A, and overall led to an insulinotropic effect (Liu et al., 2006). Studies on in vitro grown cell cultures (human HepG2 liver carcinoma and 3T3-L1 murine adipocytes) have shown that anthocyanins $(\mathbf{1 0})$ and epicatechins $(\mathbf{1 1}, \mathbf{1 2})$, and the alkaloid berberine $(\mathbf{3})$ 
<smiles>O=c1c(-c2ccc(O)cc2)coc2cc(O)cc(O)c12</smiles>

9 - Genistein<smiles>[R]c1cc([C]2Oc3cc(O)cc(O)c3C[C@H]2OC(=O)c2cc(O)c(O)c(O)c2)cc(O)c1O</smiles><smiles></smiles>

11 - Epicatechin gallate (ECG) $\mathrm{R}=\mathrm{H}$ 12 - Epigallocatechin gallate (EGCG) $\mathrm{R}=\mathrm{OH}$

Fig. 4: Compounds that can restore activity of the insulin receptor

can restore activity of the insulin receptor (IR), and trigger phosphorylation of insulin receptor substrate (IRS) resulting in the activation of the PI3K/Akt2 signalling pathway which simultaneously decreases gluconeogenesis and increases glucose uptake by translocating the glucose transporter 4 (GLUT-4) from intracellular stores to the plasma membrane. The results of in vitro studies were confirmed in in vivo studies with streptozotocin (STZ)-induced diabetic rats and mice (Hajiaghaalipour et al., 2015). The ability of phytochemicals to inhibit AGEs formation is commonly measured using a relatively simple in vitro assay in which bovine serum albumin (BSA) is incubated with glucose or fructose for several days to let glycation proceed, either in the presence or absence of inhibitors (MacPherson et al., 1988; Kim \& Kim, 2003). After separation of the proteins from the sugars by dialysis, the amount of AGEs formed can be established by fluorescence 
spectrometry or by more advanced analytical techniques such as GC-MS, HPLC, ELISA, western blotting, or immunohistochemistry. The effect of several glycation inhibitors has also been established in vivo, using STZ-induced diabetic rats and mice (Xie \& Chen, 2013).

Vitamin B derivatives pyridoxamine (13) and benfotiamine (14) (Fig. 5), and the antioxidant vitamins $C$ (15) and E (16) showed promising AGE inhibiting activity in preclinical studies, though clinical trials have been rather disappointing so far (Peyroux \& Sternberg, 2006). A wide range of flavonoids has been tested for the AGEs inhibiting activity, and a structureactivity comparison indicated that particularly C3-methoxylated flavone aglycones (17) show a good promise (Xie \& Chen, 2013).<smiles>Cc1ncc(CO)c(CN)c1O</smiles>

13 - Pyridoxamine (Vit B6)<smiles>Cc1ncc(CN(C=O)CC(COP(=O)(O)O)SC(=O)c2ccccc2)c(N)n1</smiles><smiles>O=C1OC(C(O)CO)C(O)=C1O</smiles>

15 - Vitamin C<smiles>Cc1c(C)c2c(c(C)c1O)CC[C@](C)(CCC[C@H](C)CCC[C@H](C)CCCC(C)C)O2</smiles>

16 - Vitamin $E$

17 - Flavonoids

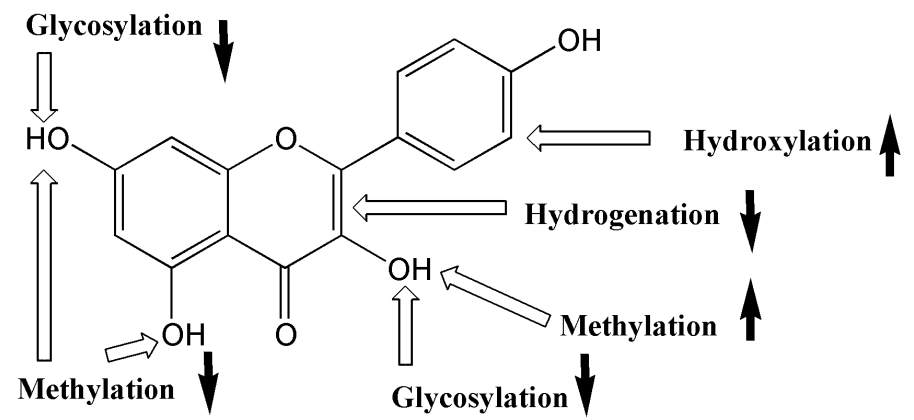

Fig. 5: Inhibitors of AGE formation

The activation of pro-inflammatory signalling pathways by AGEs (Yeh et al., 2017a) can be counteracted by the activation of anti-inflammatory signalling pathways through induction of 
transcription factor Nrf2. Best known as the transcription factor reducing oxidative stress, Nrf2 is now recognized for alleviating various causes of stress including xenobiotics, excessive nutrient /metabolite supply, inflammation or accumulation of misfolded proteins. Several modes of Nrf2 activation by phytochemicals have excellently reviewed recently (Matzinger et al., 2018). Most Nrf2-activators have been identified using mammalian in vitro cell cultures. Prominent phytochemical activators of Nrf2-signalling (Fig. 6) include

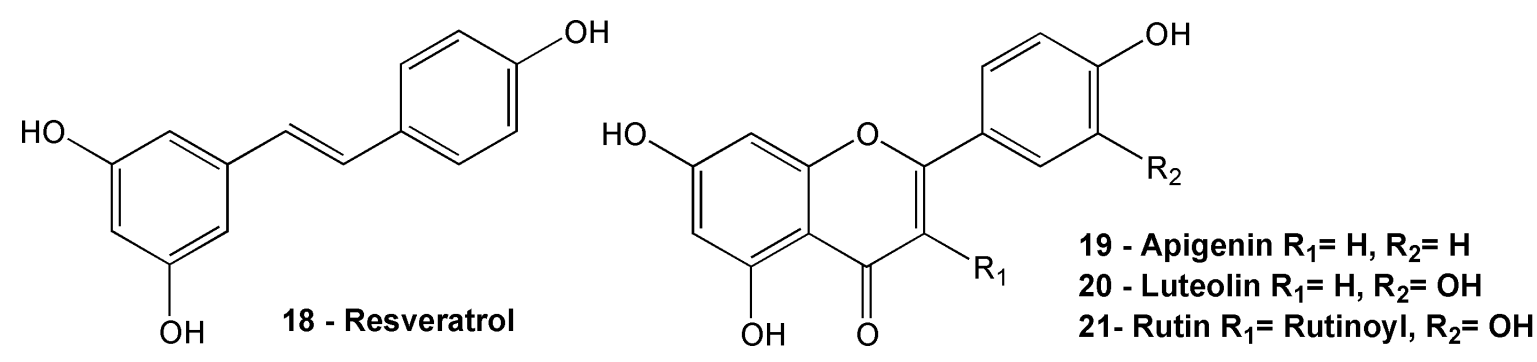<smiles>CCCCCCCC=O</smiles><smiles>COc1cc(/C=C/C(=O)CC(=O)/C=C/c2ccc(O)c(OC)c2)ccc1O</smiles><smiles>CS(=O)CCCCN=C=S</smiles>

24 - Sulphoraphane

Fig. 6: Activators of $\mathrm{Nrf2}$

resveratrol (18), flavonoids - e.g. apigenin (19), luteolin (20), rutin (21), and catechins (11, 12), and other natural compound groups e.g. cinnamic aldehyde (22), curcumin (23), sulforaphane (Matzinger et al., 2018). In a similar fashion, palmitate-induced activation of pro-inflammatory signalling pathways in human aortic endothelial cells (HAECs) could be reversed. This time, anthocyanins (10) themselves had little effect, but anthocyanin-derived metabolites (29-31) attenuated the damaging effects, even at sub-micromolar concentrations 
that are known to circulate in humans following blueberry consumption (Bharat et al., 2017). Relief of inflammation and oxidative stress is believed to allow partial restoration of the $\beta$ cells in the islets of Langerhans, and may thus indirectly contribute to increased insulin production and consequently to improved glucose homeostasis. In addition, reduction in oxidative stress correlates with reduction in most diabetic complications (Sun et al., 2020).

\section{Bioavailability}

In most in vitro bio-assays discussed so far, variable dietary phytochemicals were tested either as aglycones or as the naturally occurring glycosides. The assay results do not necessarily reflect what happens in vivo, because the compounds that are active in the target tissues (e.g. liver, pancreas, kidneys, adipose tissue) are metabolites of the dietary compounds in the form of glutathione, sufate, or glucuronate conjugates. Of all the naturally occurring glycosides, only glucosides are hydrolysed in the small intestine and subsequently absorbed as aglycones. After absorption, the aglycones are rapidly reconjugated and enter plasma and the circulatory system; a substantial part of the conjugated molecules is taken out the circulatory system in the liver as then returned into the digestive tract with bile. Other naturally occurring glycosides (e.g. galactosides, rhamnosides, rutinosides) are not absorbed at all, and in an unaltered state enter the large intestine where they are degraded by the intestinal microflora. The bacterial degradation products of dietary compounds are finally absorbed at the very distal end of the human digestive tract. These are the compounds that are ultimately available to assert their activity in the various target tissues, e.g. blueberry anthocyanins malvidin-3-glucoside (25) and cyanidin-3-glucoside (26) are broken down into the blueberry metabolites hippuric acid (27), hydroxyhippuric acid (28), benzoic acid-4- 
sulfate (29), vanillic acid-4-sulfate (30), and isovanillic acid-3-sulfate (31) (Fig. 7) (Bharat et al., 2017).<smiles></smiles>

25 - malvidin-3-glucoside (Oenin)<smiles></smiles>

26 - Cyanidin-3-glucoside (Chrysanthemin)<smiles>[R]c1ccc(C(=O)NCC(=O)O)cc1</smiles>

27 - Hippuric acid R = H

28 - 4-Hydroxyhippuric acid $\mathrm{R}=\mathrm{OH}$<smiles>[R]c1cc(C(=O)O)ccc1OS(=O)(=O)[O-]</smiles>

29 - Benzoic acid-4-sulfate $\mathrm{R}=\mathrm{H}$ 30 - Vanillic acid 4-sulfate $R=O M e$<smiles>COc1ccc(C(=O)O)cc1S(=O)(=O)[O-]</smiles>

31 - Isovanillic acid 3-sulfate

Fig. 7: Anthocyanidins and their metabolites can induce relief of inflammation and oxidative stress

For anthocyanins and other bioactive compounds in food, there is a high inter and intraindividual variation in the response to intake, and a variation in gut microbiota, that in many cases leads to contradictory results in human trials (Eker et al., 2020). In addition, hyperglycaemia, or complications linked with hyperglycaemia, are known to affect bioavailability of phytochemicals (Chen et al., 2017; Wang et al., 2012; Xiao and Högger, 2014; Xie et al., 2012). The understanding on how diabetic condition impacts on the bioavailability of polyphenols is very limited and mainly derives from in vitro and animal studies. The altered pharmacokinetics of polyphenols in diabetics is partly attributed to diabetes-associated malfunctions of liver and/or kidney characterised by modified intestinal $\beta$-glucuronidase activity and altered expression of metabolic enzymes as compared to nondiabetics (Lee et al., 2009; Xiao and Högger, 2014). Diabetes-induced changes in the gut 
microbiota may further add to the complexity of diabetic influences on the metabolism of polyphenols (Deng et al., 2007; Deng et al., 2008). Hyperglycaemia in diabetics also affects polyphenols' interactions with plasma proteins. Glucose competes with polyphenols for binding to plasma proteins (Wang et al., 2012; Du et al., 2013), and the glycated plasma proteins have weakened non-covalent interaction affinities for dietary phytochemicals (Xie et al., 2012). T2D plasma proteins were found to have up to 10 times lower affinities for polyphenols than healthy human plasma proteins (Xie et al., 2012). Moreover, polyphenols in the blood of diabetics are more inclined to interact with free radicals in plasma. As a consequence, the delivery of polyphenols to other tissues is affected which limits the exploitation of their antioxidant potential (Cao et al. 2015).

\section{Human intervention studies}

\section{Studies using whole food - berries}

Evidence on effects of consumption of fresh berries on management of the diabetic condition in humans is scarce. One study found that an acute oral dose of $40 \mathrm{~g}$ of sweetened dried cranberries (Vaccinium macrocarpon Aiton) to T2D adults, in 4 hours resulted in a decreased postprandial level of blood glucose compared to the group fed with an equicaloric amount of white bread (Wilson, 2010). Similar effects on diabetic control have been reported when using processed forms of berries including (freeze) dried, frozen and juiced. Dried cranberries, when taken at $40 \mathrm{~g}$ with a high-fat fast-food-style breakfast in an acute setting by T2D patients, led to significant reductions of $16 \%$ and $14 \%$ in postprandial glucose at $2 \mathrm{~h}$ and 4h respectively (Schell et al., 2017). The study intervention groups also experienced decreased levels of inflammatory and oxidative stress markers, i.e. interleukin 18 (IL-18) and lipid peroxidation products within the $4 \mathrm{~h}$ of post-consumption as well. Yet, the chronic 
Table 1: Human intervention studies investigating effects of whole food consumption on diabetic and inflammatory markers, antioxidant status and vascular endothelial function in T2D patients

\section{Intervention \\ group}

13 medicated

$\mathrm{T} 2 \mathrm{D}$ patients

25 medicated

T2D patients

25 medicated

T2D patients

36 unmedicated

T2D patients

$58 \mathrm{~T} 2 \mathrm{D}$ patients

42 medicated

$\mathrm{T} 2 \mathrm{D}$ patients

\section{Study design}

Randomised, single-crossover acute, controlled study

\section{Randomised} crossover,

parallel-arm, acute, controlled study

Randomised, 2phase crossover, controlled study

Randomised, double-blind, parallel-arm, acute, controlled study

Randomised, double-blind, parallel-arm, controlled study

Randomised, parallel-arm, controlled study

\section{Dose; duration}

$55 \mathrm{~g}$ raw cranberrry (RC), $40 \mathrm{~g}$

sweetened dried cranberries (SDC), $40 \mathrm{~g}$ reduced-sugar dried cranberries (RSDC), $57 \mathrm{~g}$ white bread (WB); once

$40 \mathrm{~g}$ dried cranberries (DC) with highfat-fast-food-style breakfast (974 kcal), $80 \mathrm{~g}$ banana; once

Phase I: $250 \mathrm{~g}$ frozen raspberries (FR) $85 \mathrm{~g}$ ripe banana $(\mathrm{RB})$; once.

Phase II: $250 \mathrm{~g}$ FR, $85 \mathrm{~g} \mathrm{RB}$; daily for 4 weeks

$50 \mathrm{~g}$ freeze-dried strawberries (FDS), macronutrient matched placebo powder with strawberry flavour (PP); daily for 6 weeks

1 cup (240 ml) Cranberry juice (CJ), 240 $\mathrm{mL}$ placebo drink (natural mineral water with strawberry flavour) (PD); daily for 12 weeks

$200 \mathrm{~mL}$ barberry juice (BJ), control with no intervention; daily for 8 weeks

\section{Study outcomes (significant)}

Persisted plasma glucose elevation in WB

comparing to other groups. Insulin AUC values

for RC and RSDC lower than WB or SDC.

Plasma insulin for RSDC lower at 60 min than either WB or SDC.

Decreased plasma glucose at $2 \mathrm{~h}$ and $4 \mathrm{~h}$ in DC versus banana group.

Phase I: In FR, lower levels of serum glucose at 2 and $4 \mathrm{~h}$ postprandial versus control group; levels of inflammatory markers IL- 6 and hsTNF- $\alpha$ were also lower at $4 \mathrm{~h}$ postprandial in FR versus RB. Phase II: continued lowering effects of FR on lowering IL-6 and hsTNF- $\alpha$ levels versus RB

FDS decreased C-reactive protein levels as a biomarker of inflammation and lipid peroxidation in the form of MDA (lipid peroxidation marker) at 6 weeks versus PP. FDS led to a reduction of

$\mathrm{HbA} 1 \mathrm{c}$ levels and an increase in total antioxidant status versus PP.

At 12 weeks, decreased levels of serum glucose and apo B and increased levels of serum apo A-1 and Paraoxonase-1 (PON-1) activity in CJ compared to their initial values and also with $\mathrm{PD}$

After intervention, SBP, DBP, FBS, TC and TC levels decreased and PON-1 as an antioxidant enzyme increased in $\mathrm{BJ}$ versus control.

\section{Reference}

Wilson et al. (2010)

Schell et al. (2017)

Schell et al. (2019)

Moazen et al. (2013)

Shidfar et al. (2012b)

Lazavi et al. (2018) 
$10 \mathrm{~T} 2 \mathrm{D}$ patients for feasibility study (FS). 41 medicated T2D patients for efficacy study (ES).

$10 \mathrm{~T} 2 \mathrm{D}$ patients

Randomised, double-blind, crossover, controlled study

11 overweight and non-insulin treated $\mathrm{T} 2 \mathrm{D}$ patients 80 T2D patients

\section{A single-dose} intervention study

Randomised,

double-blind, controlled study
FS: cocoa drinks containing $75 \mathrm{mg}, 371$ $\mathrm{mg}$ or $963 \mathrm{mg}$ of flavanols; once.

ES: 3 doses of cocoa drink (CD-ES)

containing $321 \mathrm{mg}$ flavanols per dose daily; 30 days.

13.5 g high-polyphenol (PL) chocolate (containing 3.5\% PL) (HPC), $13.5 \mathrm{~g}$ low-PL chocolate containing $0.9 \% \mathrm{PL}$ (LPC); once

$25 \mathrm{~mL} /$ day extra-virgin olive oil (EVOO) containing $577 \mathrm{mg}$ of phenolic compounds / kg; 4 weeks

$226.8 \mathrm{mg}$ Brazilian green propolis (BGP), the placebo; daily for 8 weeks
FS: A single ingestion of flavanol-containing cocoa was dose-dependently associated with significant acute increases in circulating flavanols and flow-mediated dilation (FMD) of the brachial artery assessed as the vascular function.

ES: CD-ES consumption increased baseline FMD by $30 \%$, the acute increases of FMD continued to be manifest throughout the study.

Improvement in endothelial function and decreased oxidative stress measured as the level of urinary 15-F2t-isoprostane in HPC versus LPC.

Reduced levels of fasting plasma glucose, HbA1c, aspartate aminotransferase, alanine

aminotransferase and visfatin as well as reduced BMI and body weight in EVOO

Values of blood uric acid and estimated glomerular filtration rate in patients taking the placebo became worse at 8 weeks compared to the baseline, yet this did not occur in patients consuming BGP.
Balzer et al. (2008)

Mellor et al. (2012)

\section{Santangelo et al.}

Fukuda et al. (2012) 
effects of berry consumption still remain to be tested in an appropriate study setting. Frozen raspberries (Rubus idaeus L.) also show positive impacts on diabetic conditions. An acute feed of frozen raspberries yielded significantly lower levels of blood glucose and inflammatory markers, including IL-6 and high-sensitivity tumour necrosis factor alpha (hsTNF- $\alpha$ ), within $4 \mathrm{~h}$ of postprandial phase. These anti-inflammatory effects of raspberries persisted throughout a continued 4-week supplementation (Schell et al., 2019). In another case, strawberries (Fragaria x ananassa Duchesne) in their freeze-dried form taken as a $50 \mathrm{~g}$ dose (equiv. to $500 \mathrm{~g}$ of fresh strawberries) significantly improved both inflammatory and antioxidant status of subjects with T2D, as indicated by decreased C-reactive protein and lipid peroxidation product levels respectively, after a 6-week supplementation (Moazen et al. 2013). In addition, the intervention also led to a significant reduction in $\mathrm{HbA1C}$, the marker for monitoring of glycemic management (Tanaka et al., 2011). The observed benefits of berries and their processed products in diabetic management are ascribed to their phytochemical content, predominantly anthocyanins (USDA, 2014). The clinical evidence indicates that these flavonoids have potential as adjuvants for the amelioration of diabetic conditions. When consumed in juice form, berries still deliver anti-diabetic effects in T2D adults. In a 12-week randomised and controlled trial, T2D patients who consumed one-cup $(240 \mathrm{~mL})$ of cranberry juice daily had decreased levels of fasting blood glucose at week 12 (Shidfar et al., 2012b). Similar results were reported in a barberry (Berberis vulgaris L.) juice study, where a daily dose of $200 \mathrm{~mL}$ for 8 weeks significantly improved the systolic and diastolic blood pressure, fasting blood sugar as well as blood lipid profiles, including total cholesterol and triglycerides in T2D patients (Lazavi et al., 2018). 
Table 2: Human intervention studies investigating effects of tea consumption on diabetic and inflammatory markers, weight status and vascular function in T2D patients

$\begin{array}{lll}\text { Intervention group } & \text { Study design } & \text { Dose; duration } \\ 16 \text { obese, insulin- } & \text { Randomised, } & 100 \mathrm{ml} \text { black tea }(\mathrm{BT}), 100 \mathrm{~mL} \\ \text { resistant males } & \begin{array}{l}\text { controlled, cross- } \\ \text { over study }\end{array} & \begin{array}{l}\text { beetroot juice (BJ), 100 mL control } \\ \text { (water); once }\end{array}\end{array}$

50 T2D patients

16 T2D patients
Randomised, double-blind, controlled study

Randomised, controlled, crossover study
3 cups $(600 \mathrm{~mL})$ Diabetea tea ${ }^{\mathrm{TM}}$ extract (DT), daily for 12 weeks
3 cups $(600 \mathrm{~mL}$ ) placebo extract (PL);

$6 \mathrm{~g}$ Gynostemma pentaphyllum (GP) tea, 6 g placebo green tea (PGT); daily for 4 weeks

\section{Study outcomes (significant)}

BT decreased vascular resistance (VR)

compared to control in conduit, resistance and micro-vessels. BJ decreased postprandial VR in resistance vessels, but not in conduit artery and micro-vessels. Postprandial insulin response was attenuated by $\sim 29 \%$ after tea, but not beetroot juice.

DT suppressed CD4+ T cell expression of IL-1 beta and IL-8 and up-regulated the expression of IL-10 and the Treg/IL-17 ratio. A significant decrease in $\mathrm{HbAlc}$ and LDL was observed at the end of the study period in DT.

\section{Reference}

Fuchs et al. (2016)

Mahmoud et al.

(2016)

The FBG and steady-state plasma glucose were lower after GP treatment compared to PGT treatment. The levels of FPG in PGT group were slightly reduced to 0.2 +/- 1.5 versus $1.9+/-1.0 \mathrm{mmol} / \mathrm{L}$ in GP group. 
43 non-insulin Randomised,

treated T2D patients double-blind,

parallel-arm,

controlled study
Green tea containing $582.8 \mathrm{mg}$ of catechins (catechin group), green tea containing $96.3 \mathrm{mg}$ of catechins (control group); daily for 12 weeks.
The decrease in waist circumference was greater in the catechin group versus control group. Adiponectin, which is negatively correlated with visceral adiposity, increased only in the catechin group. The increase in plasma insulin (Ins)at week 12 was greater in the catechin group than in the control group. In patients treated with insulinotropic agents, the increase in insulin levels was observed only in the catechin group, and the decrease in HbA1c at week 12 was greater in the catechin group than in the control group.

4C had a decrease in body weight, BMI, waist circumference, and SBP.

parallel, controlled study

55 T2D patients
4 cups of green tea (4C), 2 cups of green tea (2C), no green tea (0C); daily for two months.

$9 \mathrm{~g}$ green tea contained in $900 \mathrm{~mL}$ water, control; daily for 4 weeks.
Randomised, crossover, controlled study
Inflammatory markers, such as hsCRP and IL-6, blood glucose, lipid profiles, insulin resistance, serum adiponectin levels, brachial-ankle pulse wave velocity were unchanged after green tea consumption.
Nagao et al. 2009
Mousavi et al. 2013

Ryu et al. 2006 
100 T2D patients Randomized, parallel study
$150 \mathrm{~mL}$ Sour tea (ST), $150 \mathrm{~mL}$ green tea (GT); three times a day for 4 weeks.
HDL-c increased in both groups. The median of FBI in GT showed a decrease unlike the ST which showed an increase. The median of HOMA-IR after the intervention in GT showed lower levels than the ST. The median of b\% only in ST showed increase after the intervention. The mean of S\% only in ST showed a decrease after the intervention.
Mozaffari-Khosravi

et al. 2014a 
Further studies using whole food-Cocoa-beans, virgin olive oil, propolis

Cocoa (Theobroma cacao L.) -based food products have been found owning therapeutic potential in reducing the risk of vascular dysfunction among medicated diabetic patients. An acute consumption of cocoa powder-formulated drinks rich in flavanols, predominantly epicatechins (11-12), caused a significant improvement in the vascular endothelial function of medicated T2D patients (Balzer et al., 2008). The effects went in a dose-dependent manner when cocoa drinks containing flavanol contents of $75 \mathrm{mg}, 371 \mathrm{mg}$ and $963 \mathrm{mg}$ were applied sequentially to the patients on 3 separate occasions (Balzer et al., 2008). The cardioprotective benefits of the cocoa drinks were also testified at a flavanol content level of $321 \mathrm{mg}$ per dose in a 30-day intervention with 3 doses ingested daily, following the acute study (Balzer et al., 2008). Similar acute effects of cocoa on vascular endothelial health were manifested in the form of high-polyphenol contained $(3.5 \% \mathrm{w} / \mathrm{w})$ chocolate after a $2 \mathrm{~h}$ consumption among T2D patients with or without medication. In addition, the protective role of the flavanol-rich chocolate against the acute hyperglycaemia-induced oxidative stress were also shown in those patients (Mellor et al., 2012). Epicatechins (11-12), as the predominant form of polyphenols found in cocoa-based food and beverages, have been suggested be responsible for the anti-diabetic outcomes, due to their known properties of improving the serum antioxidative status and increasing nitric oxide levels via its modulation on nitric oxide synthase (Hollman et al., 2011). Periodic hyperglycaemia as a common feature of diabetes can cause an increased level of oxidative stress, which can then deteriorate the vascular endothelial functions (Brownlee, 2001). This may partly account how phytochemical antioxidants deliver merits to the anti-diabetic battles.

Extra-virgin olive oil, pressed from the fruits of Olea europaea L., and commonly consumed as part of the Mediterranean diet, has drawn considerable interest for its benefits in controlling diabetic conditions. In a 4-week intervention study, overweight T2D patients 
Table 3: Human intervention studies investigating effects of fruit extract consumption on diabetic markers and antioxidant status in T2D patients

\section{Intervention group}

37 T2D patients

resistant to

conventional oral

anti-hyperglycaemic

drugs

13 T2D patients

31 T2D patients

60 T2D patients

8 male T2D patients

\section{Study design}

Randomised, double-

blind, controlled

study

Randomised, double-

blind, controlled

study

Randomised, double- $\quad 3 \mathrm{~g} / \mathrm{d}$ Berberis vulgaris fruit extract

blind, controlled

study

Randomised, doubleblind, controlled study

Randomised,

crossover, acute,

controlled study

\section{Dose; duration}

A capsule of $350 \mathrm{mg}$ whortleberry fruit extract, placebo; every $8 \mathrm{~h}$ for 2 months

$1 \mathrm{mg}$ Berberis fruit extract (BFE), placebo; twice daily for 2 months (BVFE), placebo; 3 months

A capsule of Cornus mas L. fruit extract (FE) containing $150 \mathrm{mg}$ anthocyanins; placebo; 2 capsules twice daily for 6 weeks

$0.47 \mathrm{~g}$ standardised bilberry extract (BE) (36\% (w/w) anthocyanins) which equates to about $50 \mathrm{~g}$ of fresh bilberries, placebo; once

\section{Study outcomes (significant)}

Reference

The extract lowered the levels of FBG, 2- Kianbakht et al. $\mathrm{h}$ postprandial glucose, and $\mathrm{HbA} 1 \mathrm{c}(\mathrm{p}=$ $0.007, \mathrm{p} 0.05)$ versus placebo after the intervention.

BFE had a reduction in serum glucose and HbA1c levels during the 8 weeks of study.

Moazezi \& Qujeq (2014)

There were decreases in serum TG, TC, LDL-c, apo B, glucose, and insulin and a significant increase in TAC at the end of the study in BVFE versus placebo. There were differences in serum TG, TC, LDLc, apoB, glucose, insulin, TAC, and insulin resistance between the two groups at the end of the study.

The insulin level increased while the

Soltani et al.

$\mathrm{HbA} 1 \mathrm{C}$ and TG levels decresaed in FE versus placebo.

$\mathrm{BE}$ had a significant decrease in the incremental AUC for both glucose and insulin versus placebo.
Shidfar et al.
Hoggard et al.

2013 
49 T2D patients

Randomised, double-

blind, placebo-

controlled, multiple-

dose study
$375 \mathrm{mg}$ capsule containing $150 \mathrm{mg}$ of green tea catechins (equivalent to the amount in 7 cups of green tea) and 75 $\mathrm{mg}$ of black tea theaflavins (equivalent to the amount in 35 cups of black tea),

$375 \mathrm{mg}$ capsule of cellulose; daily for 3 months
The changes in glycosylated hemoglobin were not significantly different between study arms. No hypoglycemic effect of extract of green or black tea was found.
Mackenzie et al.

2007 
showed significantly improved glycaemic control status, body mass index (BMI) and circulating profile of inflammatory adipocytokines after a daily consumption of highpolyphenol extra virgin olive oil containing $577 \mathrm{mg}$ of phenolic compounds/kg (Santangelo et al., 2016).

Another type of food, Brazilian green propolis which is less commonly consumed compared to the foods aforementioned, was studied in an 8-week feeding trial. T2D adults who received $226.8 \mathrm{mg} /$ day of the propolis did not show significant improvement of the hyperglycaemic state, but the treatment prevented a reduction of glomerular filtration rate and concomitant build-up of uric acid that is commonly seen in T2D patients (Fukuda et al., 2015).

\section{Beverage consumption - Black tea}

In addition to fruit juice, several research studies paid attention to tea (Camellia sinensis (L.) Kuntze), one of the most commonly consumed beverages in the world, and regarded its antidiabetic functions. Ingestion of $100 \mathrm{~mL}$ of flavonoid-rich black tea resulted in decreased peripheral vascular resistance (VR) and an attenuation of postprandial insulin response by approximately $29 \%$ among a group of obese and insulin-resistant male adults within $3 \mathrm{~h}$ after consumption (Fuchs et al., 2016). Beet juice, pressed from the taproot of Beta vulgaris L., is rich in nitrate and a dietary source of nitric oxide (Lundberg et al., 2006), was tested in the same study group at a level of $100 \mathrm{~mL}$, but exerted less modulating impact on the postprandial skeletal blood flow and glucose homeostasis compared to black tea. It indicated that the effects of black tea may be ascribed to its flavonoid content that has the potential of improving vascular endothelial functions (Ras et al., 2011), which can then stimulate the postprandial blood flow responses (Fuchs et al., 2016). The anti-diabetic efficacy of black tea was also examined when taken in a mixed formula with other types of medicinal plants. Diabetea tea $^{\mathrm{TM}}$, a type of herbal tea with its main constituent being black tea $(60 \% \mathrm{w} / \mathrm{w})$ and 
Table 4: Human intervention studies investigating effects of the consumption of herb and spice extract on diabetic and inflammatory markers and antioxidant status in T2D patients

Intervention group

19 well-controlled T2D patients

20 T2D patients

9 T2D patients

10 T2D patients

41 T2D patients

\section{Study design}

Randomised, double-

blind, crossover, acute,

controlled study

Randomised, crossover, controlled study

Randomised, controlled study

Randomised, acute, controlled study

Randomized, doubleblind, placebocontrolled

\section{Dose; duration}

A capsule of $6 \mathrm{~g}$ Panax ginseng, placebo (vanilla-flavoured capsulated corn starch); daily for 12 weeks

2.2 g Panax ginseng root in capsules, placebo; daily for 4 weeks

3-g American Ginseng (AG) capsules, placebo; once

3, 6, or $9 \mathrm{~g}$ ground American Ginseng (AG) root in capsules, $0 \mathrm{~g}$ (placebo); once

$2 \mathrm{~g} /$ day of ginger powder (GP) supplement, lactose as placebo (LP); 12 weeks

\section{Study outcomes (significant data)}

Decreased 75 g-OGTT-PG indices, fastingPI and 75 g-OGTT-PI indices, and increased fasting-ISI (HOMA) and $75 \mathrm{~g}$ OGTT-ISI versus placebo.

Great decrease in HOMA-IR after ginseng intervention. Lower fasting plasma glucose in ginseng group versus placebo group.

Differences found in postprandial glycaemia between $\mathrm{AG}$ and placebo when capsules were taken $40 \mathrm{~min}$ before or together with $25 \mathrm{~g}$ oral glucose challenge

Treatment $(0,3,6$, and $9 \mathrm{~g} \mathrm{AG})$ affected postprandial glycaemia. compared with $0 \mathrm{~g}$ (placebo). Either dose of AG reduced AUC and incremental glycemia at $30 \mathrm{~min}, 45 \mathrm{~min}$ and $120 \mathrm{~min}$ respectively.

Reduced levels of FBG, HbA1c, apo B, apo B/apo A-I and MDA in GP after

intervention in comparison to their baseline and LP. The level of apolipoprotein A-I increased in GP.

\section{Reference}

Vuksan et al. 2008

Ma et al. 2008

Vuksan et al. 2000a

Vuksan et al. 2000b

Khandouzi et al. (2015) 
88 T2D patients

Randomized, double-

blind, placebo-

controlled study
3 one-gram capsules containing ginger powder (GP), 3 one-gram control capsules; daily for 8 weeks blind, parallel, controlled study

$40 \mathrm{~T} 2 \mathrm{D}$ patients

$51 \mathrm{~T} 2 \mathrm{D}$ patients

$51 \mathrm{~T} 2 \mathrm{D}$ patients

$79 \mathrm{~T} 2 \mathrm{D}$ patients

$42 \mathrm{~T} 2 \mathrm{D}$ patients

204 T2D patients
Randomized, doubleblind, placebocontrolled study

Randomized, doubleblind, placebocontrolled study

Randomized, placebocontrolled study

Randomized, doubleblind, placebocontrolled study

Randomized, doubleblind, placebocontrolled study

Randomized, single-

blind, parallel,

controlled study
$3 \mathrm{~g}$ ginger dried powder (GDP), control; daily for 8 weeks

$3 \mathrm{~g}$ of Momordica charantia fruit and seed extract in capsules, placebo; 3 months

$6 \mathrm{~g}$ of Momordica charantia fruit and seed extract in capsules, placebo; 1 month

1,3 , or 6 g cinnamon daily, respectively, placebo; 40 days

$3 \mathrm{~g}$ a cinnamon extract powder (CE), a placebo capsule (PC); three times a day for 4 months

$500 \mathrm{mg}$ cinnamon (C. cassia) in a capsule, $500 \mathrm{mg}$ placebo (wheat flour) in a capsule; twice daily for 3 months

$3 \mathrm{~g}$ cinnamon dried powder

(CDP), control; daily for 8 weeks
FBG mean showed a decrease in ginger, whereas control had an increase. Similar variation found in $\mathrm{HbA} 1 \mathrm{c}$. Differences found in the median of fasting insulin level, IS\% and HOMA-IR between GP and control before and after the intervention. QUICKI mean increased more in GP after intervention versus control.

GDP had beneficial effects on TC, LDL, and HDL levels versus control.

Mozaffari-Khosravi et

al. (2014b)

Azimi et al. (2014)

No significant change in $\mathrm{HbA1c}$ or FBG values.

No significant change in $\mathrm{HbA1c}$ or FBG values.

All three levels of cinnamon reduced the mean FBG, TG, LDL and TC levels

Higher reduction of FBG in CE than PC between pre- and post-intervention

No significant differences between the cinnamon and placebo groups in the change in any measure of FBG, TC, LDL, HDL, TG and insulin levels from baseline to 3 months

CDP had beneficial effects on TC, LDL, and HDL levels versus control.
Dans et al. (2007)

John et al. (2003)

Khan et al. (2003)

Mang et al. (2006)

Blevins et al. (2007)

Azimi et al. (2014) 
60 T2D patients on metformin therapy
Randomized, placebocontrolled study
2 g turmeric supplements (TS); control with no treatment; daily for 4 weeks
Decreased FBG and HbA1c levels, an

reduction in MDA and hsCRP

(inflammatory marker) levels, and enhanced

total antioxidant status in TS versus control.

TS had improved lipid metabolism shown in the levels of LDL, non-HDL cholesterol and LDL/HDL ratio.
Maithili Karpaga Selvi et al. (2015) 
the remaining comprising 12 other ground dried medicinal herbs, was given to medicated T2D patients at a daily dose of 3 cups (equiv. $7.5 \mathrm{~g}$ dry tea) for a period of 12 weeks (Mahmoud et al., 2016). Positive results were seen as a significant reduction of the concentration of HbA1c and low-density lipoprotein (LDL), and also a suppression of inflammatory markers among patients. It was suggested that flavonoids, triterpenes and phytosterol contents contribute to the anti-diabetic properties of the tea. Another type of herbal tea called Jiaogulan (Gynostemma pentaphyllum Thunb.) tea demonstrated a capacity of reducing the fasting plasma glucose level and improving the insulin sensitivity in T2D patients when consumed at $6 \mathrm{~g}$ daily for 4 weeks (Huyen et al., 2013). Jiaogulan is a wild herb native to China and Vietnam, where it has been widely used as a medicinal herb for prevention and amelioration of diabetes. The potential of glycaemic control of this herb in T2D, is suggested be attributed to its dammarane-type triterpenoids (32) (Fig. 8) (Huyen et al., 2010; Huyen et al., 2012). To date, limited studies have examined the effects of green tea in diabetic management, yet study outcomes appear to be mixed in the current evidence. In the study on the Jiaogulan herbal tea (Huyen et al., 2013), green tea (Camellia sinensis (L.) Kunze) was used as the placebo consumed at a dose of $6 \mathrm{~g}$ for 4 weeks. However, the latter exerted fewer effects on the fasting blood glucose status and also yielded a lower level of insulin sensitivity measured by the values of the steady-state-plasma. In a study among T2D patients, a six-fold increment in the ingestion dose of catechins (11-12) (from $96.3 \mathrm{mg}$ to $582.8 \mathrm{mg}$ daily) delivered as green tea led to significantly greater reductions in both waist circumference and $\mathrm{HbA} 1 \mathrm{c}$ levels after a 12-week intervention, with the latter effect only found in patients receiving insulinotropic agents (Nagao et al. 2009). In general, there was no significant difference in plasma glucose and HbA1c between the two groups. Besides, the 

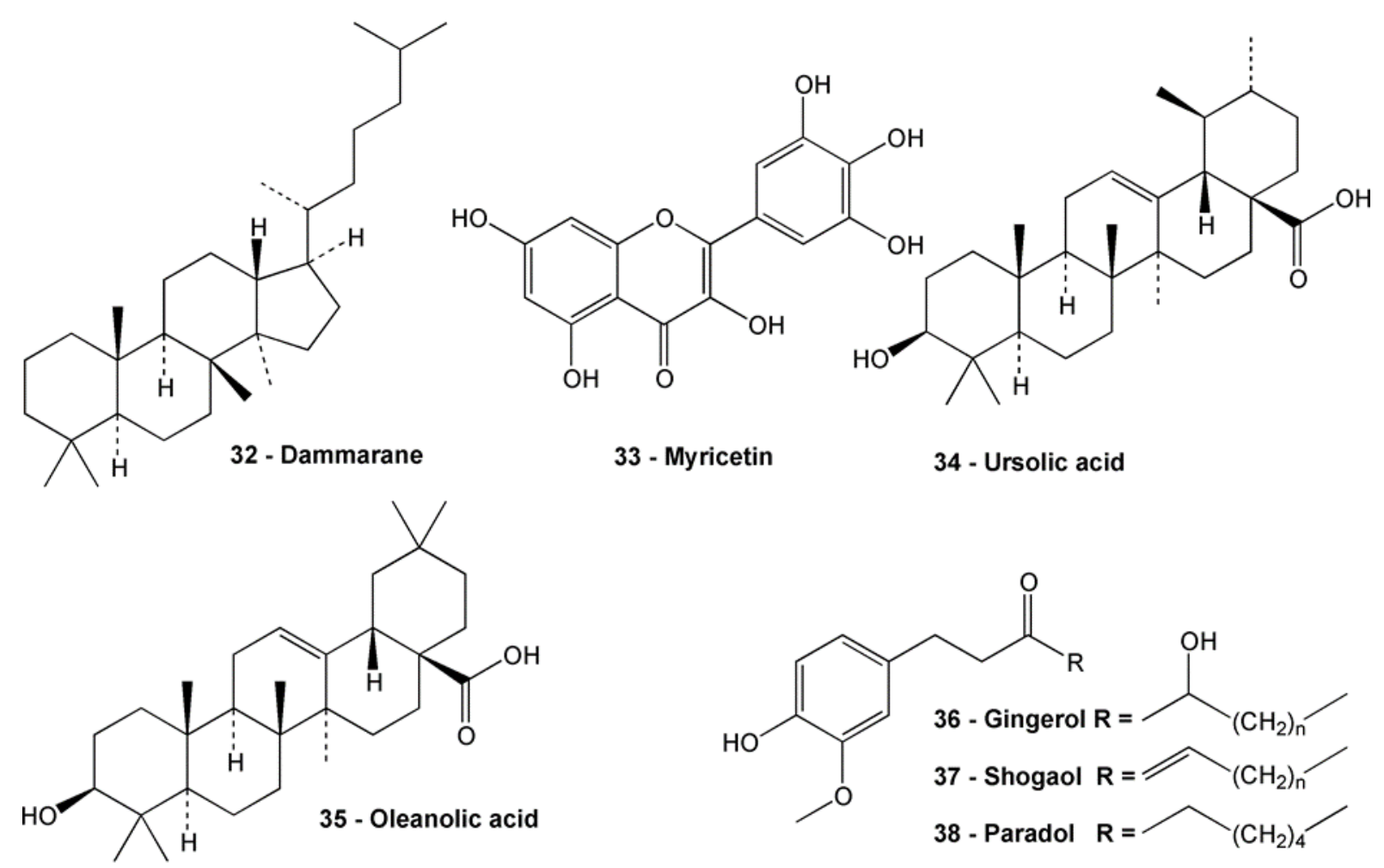<smiles>[R]C(=O)CCc1ccc(O)c(OC)c1</smiles>

Fig. 8: Phytochemicals from cornelian cherry (Cornus spec.), ginseng and ginger can restore glucose homeostasis

only significant increases in serum insulin and adiponectin that is negatively linked to visceral adiposity were observed in the higher-catechin-dosed group only (Nagao et al., 2009). This represents the potential of using green tea as an agent for HbA1c-control and weight management for T2D patients. The benefits of green tea on weight control was also found among T2D patients when ingested with four cups of green tea (prepared using $2.5 \mathrm{~g}$ tea bags in $200 \mathrm{~mL}$ of boiling water) for a period of 2 months. In addition, a reduction in systolic blood pressure also appeared post intervention. However, no effects were detected on glucose metabolic and oxidative stress markers (Mousavi et al., 2013). Catechins were suggested the main player for improving the anthropometric measures of patients (Nagao et al., 2007; Chantre et al., 2002). Similarly, green tea seemed to be ineffective in modulating the inflammatory status and arterial stiffness among T2D participants after their consumption of $9 \mathrm{~g}$ of green tea infused in $900 \mathrm{~mL}$ of water daily for 4 weeks (Ryu et al. 2006). Green tea, 
when compared to sour tea (Hibiscus sabdariffa L.), showed a better outcome in lowering the level of insulin resistance measured by homeostasis model assessment of insulin resistance among T2D patients at an ingested dose of $3 \mathrm{~g} /$ tea bag in $150 \mathrm{~mL}$ of hot water for 3 times a day over 4 weeks (Mozaffari-Khosravi et al. 2014). Based on the evidence above, the antidiabetic effect of green tea remains inconclusive and requires further exploration.

\section{Plant food extracts}

The antidiabetic effects of phytochemicals are not limited to whole foods, but also evidenced in studies using fruit extracts as the intervention foods. Caucasian whortleberry (Vaccinium arctostaphylos L.) was examined in an intervention study testing its efficacy of glycaemic control in T2D patients who were resistant to conventional anti-hyperglycaemic drugs (Kianbakht et al. 2013). $350 \mathrm{mg}$ of the whortleberry fruit hydroalcoholic extract was delivered in a form of capsule containing excipient weighted at $19.2 \% \mathrm{w} / \mathrm{w}$ to patients for every $8 \mathrm{~h}$ for 2 months in combination with anti-hyperglycaemic drugs. The result was a significant reduction of fasting blood glucose, 2h-postprandial glucose and HbA1c levels in patients. The safety of its consumption was also testified. Thus, whortleberry fruits were shown to exert safe and beneficial effects in enhancing glycaemic control to a greater extent than using anti-hyperglycaemic drugs solely in diabetic patients (Kianbakht et al. 2013). Anthocyanins (10) were supposed to account for the anti-glycaemic action (Kianbakht et al. 2013). Apart from anthocyanins, whortleberries are also known to contain chlorogenic acid (7) (Abidov et al. 2006) and myricetin (33) (Fig. 8) (Ayaz et al. 2005), which might potentially contribute to the glycaemic control capacity of the fruits (van Dijk et al. 2009; Ong et al. 2000). In a study of the similar research setting involving T2D patients who went on a 2-month intervention with $1 \mathrm{mg}$ of barberry (Berberis fruit) extract supplementation delivered in a capsule twice daily (Moazezi and Qujeq, 2014). The barberry fruit extract 
exhibited noticeable effects on glucose metabolism regulation in patients who experienced significantly reduced serum glucose and $\mathrm{HbA} 1 \mathrm{c}$ levels post intervention (Moazezi and Qujeq, 2014). Besides, Shidfar et al. (2012a) also revealed the potential of barberry extract on improving blood lipid profile favourable to cardiovascular health, enhancing the Total Antioxidant Capacity and improving the glucose metabolism of T2D patients using a higher dose at $3 \mathrm{~g} / \mathrm{d}$ for a duration of 3 months (Shidfar et al. 2012a). The mechanism for those observed effects was suggested be ascribed to the anti-diabetic actions of berberine (3) which is the main active alkaloid found in barberry at a content level of 5.2-7.7\% (Shidfar et al., 2012a). This notion is also supported by studies using berberine (3) on its own ingested at a dose of $500 \mathrm{mg}$ 2-3 times a day for 12-13 weeks among newly diagnosed T2D patients (Yin et al. 2008; Dange et al. 2016). Both studies confirmed the positive modulating effect of berberine (3) on glucose and lipid metabolism in patients, which was comparable to that of metformin (1). The observed benefits may be attributed to the induction of glycolysis pathway and/or inhibition of the glucosidase enzymes acted by berberine (3), as previously suggested by (Yin et al. 2008; Zhang et al. 2008). Another rich source of anthocyanins (10), cornelian cherry (Cornus mas L.) extract, was tested on 60 T2D patients that took 2 capsules twice daily for 6 weeks, with each capsule containing $150 \mathrm{mg}$ of anthocyanins (10). The intervention yielded improvements in glycaemic control reflected by increased insulin level and decreased levels of HbA1c and plasma triglycerides (Soltani et al., 2015). Anthocyanin contents of the fruit may be accountable for the observed effects, based on the previous in vitro (Jayaprakasam et al. 2005) and animal studies (Jayaprakasam et al. 2006). In addition, the triterpenoids ursolic acid (34) (Zhang et al. 2006) and oleanolic acid (35) (Fig. 8) (Hsu et al. 2006), present in the fruit have been given the merit for possibly playing a role in patient's glucose homeostasis together with anthocyanins (10). Anti-diabetic properties of plant fruit extract have also been illustrated in an acute setting. Bilberry (Vaccinium myrtillus L.) extract 
as the test food was given to individual T2D patients at a dose of $0.47 \mathrm{~g}(36 \% \mathrm{w} / \mathrm{w}$ anthocyanins (10), equating to about $50 \mathrm{~g}$ of fresh bilberries) contained in a single capsule (Hoggard et al. 2013). Mixed results were obtained including significant improvements in postprandial glycaemic response at 120,150 and 180 minutes post consumption, and no changes were found in examined markers of inflammation and oxidation during the period of 300 min after dosage (Hoggard et al. 2013). The positive impact on lowering glycaemic response may be linked to the actions of the anthocyanin (10) contents of the fruit (Cai et al. 2011), typically cyanidin-3-galactoside (26) (Adisakwattana et al. 2009) and oligomeric procyanidins (Schäfer and Högger, 2007; Kumar et al. 2011). Those bioactive components have shown the potency of reducing the breakdown of carbohydrates via their inhibitory actions on $\alpha$-glucosidase in vitro (Adisakwattana et al. 2009; Schäfer and Högger, 2007). In contrast to the intervention trials with tea as a beverage (Fuchs et al., 2016), capsules with dried standardised tea extract did not show convincing results in T2D patients (Mackenzie et al. 2007). A mixture of decaffeinated green tea and black tea extract was ingested at two different doses (375 $\mathrm{mg}$ and $750 \mathrm{mg}$ in a capsule per day) with each arm lasting for 3 months among T2D patients, $80 \%$ of whom being on hypoglycaemic medication. Despite the concentrated polyphenol content of the test capsules, i.e. the $375 \mathrm{mg}$ capsule was constituted of $150 \mathrm{mg}$ of green tea catechins (equating to 7 cups of green tea) and $75 \mathrm{mg}$ of black tea theaflavins (equating to 35 cups of black tea), the glycaemic responses between the test foods and placebo formula did not vary significantly among patients after the intervention (Mackenzie et al. 2007).

\section{Medicinal herbs and spices in a powder form}

Apart from the approach of using whole-foods, their extract or beverages, phytochemicals are traded abundantly in the form of ground herbal or spice powders. Ginseng, including both 
American ginseng (Panax quinquefolius L.) and Asian ginseng (Panax ginseng C.A Meyer), has attracted emerging interest for its glycaemic control potency for T2D. Panax ginseng, when dosed as capsules at a daily intake level of $6 \mathrm{~g}$ per T2D patient for 12 weeks, delivered favourable effects in glycaemic control regarding modulation of plasma glucose and insulin levels for healthy T2D patients. Still, HbA1c level remained unchanged throughout the intervention (Vuksan et al., 2008). The hypoglycaemic and insulin-sensitising effect of Panax ginseng was preserved when the ingestion dose dropped to around $2.2 \mathrm{~g}$ per day for a shorter intervention period of 4 weeks among well-controlled T2D patients by either habitual diet or hypoglycaemic agents (Ma et al. 2008). Yet, although insulin resistance decreased significantly compared to that observed in the placebo group, the plasma insulin levels remained unaffected, which contrasted with results of a previous study (Vuksan et al., 2008). No effects were shown on oxidative stress and antioxidant capacity markers either (Ma et al., 2008), which might be due to the low level of antioxidant capacity of the supplement used (Ma et al., 2008), as compared to that of other plant foods, i.e. fruits and vegetables and teas when using the same assessment technique, i.e. FRAP assay (Szeto et al., 2002). The active components of ginseng, i.e. ginsenosides - glycosides of dammarane triterpenoids (32), were hypothesised to be accountable for the anti-diabetic effects of ginseng supplementation (Sievenpiper et al., 2004). However, due to the large variability among ginsenoside composition of ginseng (Vuksan et al., 2008) and the unknown bioactivity profile of the individual ginsenosides, the mechanistic basis for the clinical observations remains as yet unclear. Two acute intervention studies found that ground American ginseng, when given as a $3 \mathrm{~g}$-capsule per person, T2D patients experienced significant reductions in postprandial glycaemia, with the reduction of incremental glycaemia occurring as early as 30 min postconsumption as compared to the placebo group (Vuksan et al., 2000a, b). Again, the ginsenosides were suggested to be the main factor for mediation of the glycaemic response in 
patients, but other bioactive components of ginseng including polysaccharides (ginsenans) and peptidoglycan (panaxans) may also contribute to the global effects of ginseng (Attele et al. 1999). Enhancement of nitric oxide synthesis via the action of ginsenosides (Gillis, 1997) is regarded as one of the plausible mechanistic explanations for the improved insulin sensitivity and carbohydrate metabolism resulted from ginseng supplementation (Roy et al. 1998; Spinas et al. 1998).

Ginger (Zingiber officinale Roscoe), as another type of herbal plant, has shown positive effects on regulating glucose homeostasis, improving blood lipid profile and enhancing antioxidant capacity when delivered as ground rhizome powders to T2D patients (Khandouzi et al. 2015; Mozaffari-Khosravi et al. 2014b; Azimi et al. 2014). The tested doses used ranged from $2 \mathrm{~g}$ to $3 \mathrm{~g}$ per day over an intervention period of 8 or 12 weeks among T2D patients. The reported beneficial effects of ginger supplementation may be attributed to its bioactive and also antioxidant components typically gingerol (36), shogaol (37) and paradol (38) (Fig. 8) (Fuhrman et al. 2000; Lebda et al. 2012). In contrast, a similar dose of bitter melon (Momordica charantia L.) fruit and extract ingested to T2D patients at a dose of $3 \mathrm{~g}$ or $6 \mathrm{~g}$ for either 3 months or 1 month respectively has not given any significant changes in markers of glycaemic control, yet, no side effects were documented (Dans et al. 2007; John et al. 2003). Other common spices have been looked at in studies recruiting different intervention settings. Cinnamon (Cinnamomum verum J.Presl.) bark has exerted some extent of glycaemic control in T2D patients with moderate effects shown on fasting blood glucose level only, yet evidence has been mixed among studies using different doses (1g, $3 \mathrm{~g}$ or $6 \mathrm{~g}$ ) and durations of intervention (40 days, 8 weeks, 4 months or 3 months), as well as recruiting T2D patients at various diabetic management status (Khan et al. 2003; Mang et al. 2006; Blevins et al. 2007; Azimi et al. 2014). Similarly, cinnamon (3g/day), cardamom (Elettaria cardamomum (L.) Maton) small seed pods (3g/day) and saffron (Crocus sativus L.) stamens 
Table 5: Key phytochemicals mentioned in the literature, their modes of action and molecular targets

\section{Compound class \\ Modes of antidiabetic actions Molecular target}

Catechins

Anthocyanidins

Proanthocyanidins
Modulate glucose absorption and uptake, reduce glycaemia. Reduce lipid absorption, regulate lipid profile. Improve insulin resistance.

Inhibition of oxidative stress and reduce blood glucose. Improve insulin resistance, regulate blood lipid profile. Stimulate insulin secretion

Reducing carbohydrate digestion, modulating hepatic glucose metabolism. Modulate Pancreatic $\beta$-cell functions.

Protecting against diabetic neuropathy.
Pancreatic $\alpha$-glucosidase, $\alpha$-amylase and maltase, $\mathrm{Na}^{+}$-dependent glucose transporter (SGLT1), AMPK

activation. Bile acid metabolism and lipogenesis in hepatic cells. JNKactivated signalling pathway,

expresssion of antioxidant genes and PTP1B.

Endogenous antioxidant enzymes and islet $\beta$ cells. Adipocytes, insulin pathway activation via FoxO1, TNF- $\alpha$. Expression of intracellular $\mathrm{Ca}^{2+}$ signalling pathway and glucose transport-related gene (Glut2), DPPIV and its substrate GLP-1, mRNA

expression of insulin receptor-related genes.

$\alpha$-glycosidase. Hepatic glucokinase activity, phosphoenolpyruvate carboxykinase, activation of AMPK and PI3K/Akt pathways to decrease glucose-6-phosphatase, insulin signalling pathways. Oxidative stress, insulin secretion and $\beta$-cell survival. Endoplasmic reticulum (ER) stress modulation and pulmonary arteries.

\section{Type of \\ study}

In vitro, Kim et al., 2013.

animal and Kobayashi et al.,2000

human Li et al., 2018a;

studies Li et al., 2018b

Mi et al., 2018.

Shimizu et al., 2000;

Solinas \& Becattini, 2016

Tsuneki et al., 2004;

Ueda et al., 2010;

Zhong et al., 2006.

Roy et al., 2008;

animal Tsuda et al., 1999;

Zhu et al., 2012;

Yan \& Zheng, 2017.

Takikawa et al., 2010

Guo et al., 2012.

Sun et al., 2018;

Johnson \& Mejia, 2016.

In vitro,

animal

Johnson, et al., 2013;

Lee, et al., 2007;

Schafer \& Hogger, 2007;

Zhang et al., 2009;

Bang \& Choung, 2014;

Cordero-Herrera, et al., 2013 ;

Kurimoto et al., 2013;

Yang \& Chan, 2017.

Ding et al., 2014 ;

Pinna et al., 2017 
Procyanidins

Reduce blood glucose and macronutrient digestion. Improve insulin sensitivity, insulin resistance and hepatic gluconeogenesis. Promote glucose homeostasis. Prevent $\beta$-cell dysfunction.

Modulate hepatic glucose metabolism. Improve glucose homeostasis. Promote glucose uptake and intracellular transport. Prevent insulin resistance. Enhance $\beta$-cell function and insulin secretion. Antioxidant defence enhancement in pancreatic tissue.
Liver lipogenesis, insulin and AMPK signalling pathways' activation for inducing the translocation of GLUT4 in skeletal muscle, intestinal amylases, proteases and lipases. Pro-

inflammatory cytokine expression, hepatic inflammation suppression, lipid depot in the adipose tissue and liver. Islet $\beta$ cell apoptosis prevention, $\mathrm{Pdx} 1$ and Glut 2 mRNA expression, and antioxidant levels in pancreatic tissue. Hepatic $\mathrm{NAD}^{+}$biosynthesis

Modulation of glucose and glycogen metabolism enzymes. Glycogen synthase activation and glycogen phosphorylase inhibition, reduced expression of transcription factor NF$\kappa \mathrm{B}$ and pro-inflammatory cytokines (IL-1 $\beta$ and IL-6) in liver. Increased number of glucose transporter GLUT4 and its translocation to plasma membrane of myocyte via PI3K-Akt pathway. Fatty acid oxidation promotion, and decreased activity of glucokinase in skeletal muscle.

Caspase-3 inhibition for preventing $\beta$ cell apoptosis. Activity of antioxidant enzymes (CAT, SOD, GPx, and glutathione-S-transferase). in vitro,

animal

studies

Animal and

human

studies

\section{9;}

Andrade et al., 2014;

Do et al., 2012;

Deng et al., 2008;

Tan et al., 2012;

Chi et al., 2007;

Goh et al., 2014;

Chen et al., 2011;

Palsamy \& Subramanian, 2010;
Lu et al., 2011;

Chen et al., 2012;

, al., 2016;

al al., 2016;

Vazquez-Flores et al., 2018.
Cremonini, et al., 2016; 
Tannins

Curcumin

Hydroxycinnamic acids
Delay intestional glucose

digestion and absorption, and reduce blood glucose level.

Upregulate glucose transport.

Hypoglycaemic effect, protect $\beta$-cell, decrease insulin resistance, regluate lipid metabolism

Reduce blood glucose level, improve insulin resistance, increase insulin secretion and sensitivity, improve $\beta$-cell function.
Decreased oxidative stress in

pancreatic $\beta$ cells, and $\alpha$-amylase and $\alpha$-glucosidase inhibition. Stimulated phosphorylation of protein factors in the insulin-mediated glucose transport pathway.

Mitigated ER stress and oxidative stress via activated Nrf2-Keap1 antioxidant response, decreased adipogenesis and enhanced catabolism of adipotic tissues, AMPK activation and upregulation of fibroblast growth factor 21 (FGF21) amount and/or action.

Increased glukinase activity, and decreased glucose-6-phosphatase and phosphoenolpyruvate carboxykinase activities in liver; modulation of glucose metabolism enzymes, AMPactivated protein kinase activation, inhibition of adipogenesis and gluconeogenesis, protection against glucolipotoxicity-mediated oxidative stress and inflammation.
In vitro,

animal and

human

studies

In vitro,

animal and

human

studies

In vitro,

animal

studies

Kasetti et al., 2012;

Jung et al., 2007;

Ohnishi et al., 2004,

Son et al., 2011;

Pei et al., 2016;

Govindaraj \& Sorimuthu, 2015.
Kato et al., 2017;

Matsui et al., 2007;

et al., 1999;

Jin et al., 2018;

Pivari et al., 2019;

Rhid et al., 2017;

Zha et al., 2018 
(1g/day) did not exert demonstratable impacts on glycaemic control, inflammatory markers or oxidative stress among T2D patients after daily ingestion for 8 weeks (Azimi et al. 2014). In contrast, daily consumption of $2 \mathrm{~g}$ dried and powdered rhizomes of turmeric (Curcuma longa L.) for 4 weeks resulted in reduced levels of fasting blood glucose and HbA1c, improved lipid profile and enhanced antioxidant status in T2D patients (Maithili Karpaga Selvi et al. 2015).

\section{Conclusions}

The clinical evidence included in this review sheds light on the potential benefits of using certain types of plant-based whole foods or their extracts as a nutritional or therapeutic measure in ameliorating diabetic conditions and preventing the disease advancement among T2D patients. In addition to the discussed mechanisms of actions of phytochemicals on diabetic conditions, an emerging notion related to phytochemicals' interactions on the Nuclear factor erythroid 2-related factor $2(\mathrm{NrF} 2)$ has added values to further understanding the mechanistic basis of phytochemicals' roles in dietary management of chronic diseases. Recent evidence has unveiled Nrf2's regulatory role in cellular resistance to oxidants. Acting as a transcription factor, it mediates the redox disturbances induced by environmental or endogenous factors through modulating the expression of multiple antioxidant response element (MRE)-dependent genes (Ma, 2013). Besides, Nrf2 is anti-inflammatory and its deficiency results in inflammation in an experimental setting (Johnson et al., 2010; Rangasamy et al., 2004, 2005; Garbin et al., 2009; Cho et al., 2004; He \& Ma, 2012). This may be explained by the observed inhibitory actions of Nrf2 on the NF- $\mathrm{BB}$ pathway and proinflammatory cytokine production (Li et al., 2008; Ma et al., 2003). However, further 
research is still largely required to understand the exact anti-inflammatory mechanisms of Nrf2.

The phytochemicals that are considered to exert activity related to management of glycaemic control, or to prevention of diabetes-related complication, do so by acting on a variety of cellular targets and their effect often refers to transcription factors that are nodes in multiple signalling pathways. Polyphenolic flavonoids (notably EGGC) are prominently present in the literature on biologically active compounds with antidiabetic activity, as are berberine, and curcumin; in the context of drug discovery, all these compounds would be dismissed as pan assay interference substances (PAINS) (Baell \& Walters, 2014; Baell 2016). Although individual reports may present models with clear looking signalling cascades, an overall review shows that PAINS alter numerous cell functions. Currently, there is little consensus and the mechanisms underlying antidiabetic activity are poorly understood. Arguably, many biologically active dietary products may act via rather non-specific mechanism like membrane bilayer perturbation (Ingólfsson et al., 2014). These properties make the listed biologically active dietary phytochemicals unattractive objects for drug discovery programs. However, they can still explain the mode of action of many dietary compounds in the prevention of diabetes-related complications or of degenerative diseases. Repeated low level activation of anti-inflammatory responses may be sufficient to maintain cellular homeostasis by avoiding peaks and troughs, e.g. by reducing post-prandial peaks in glucose levels and concomitant oxidative stress. In this view, ameliorating dietary compounds will never have the strength of therapeutic drugs like the sulfonylureas or metformin, and are not likely either to be lead-compounds for development of novel therapeutic drugs. However, dietary phytochemicals may exert a mild activity, enough to 'nudge' cells and tissues back to a physiologically healthy homeostasis, without causing harm in the long run. 


\section{References}

Abidov M, Ramazanov A, Jimenez Del Rio M, Chkhikvishvili I (2006) Effect of Blueberin on fasting glucose, C-reactive protein and plasma aminotransferases, in female volunteers with diabetes type 2: double-blind, placebo controlled clinical study. Georgian Med News. 141: 66-72.

Adisakwattana S, Charoenlertkul P, Yibchok-Anun S (2009) alpha-Glucosidase inhibitory activity of cyanidin-3-galactoside and synergistic effect with acarbose. J Enzyme Inhib Med Chem 24(1): 65-69. DOI: 10.1080/14756360801906947

Ahangarpour A, Afshari G, Mard SA et al. (2016) Preventive effects of procyanidin A2 on glucose homeostasis, pancreatic and duodenal homebox 1, and glucose transporter 2 gene expression disturbance induced by bisphenol A in male mice. J Physiol Pharmacol 67(2), 243-252.

Andrade JM, Paraiso AF, de Oliveira MV et al. (2014) Resveratrol attenuates hepatic steatosis in high-fat fed mice by decreasing lipogenesis and inflammation. Nutrition 30(7-8), 915-919. DOI: 10.1016/j.nut.2013.11.016

Attele AS, Wu JA, Yuan CS (1999) Ginseng pharmacology: multiple constituents and multiple actions. Biochem Pharmacol 58(11): 1685-1693. DOI: 10.1016/s00062952(99)00212-9

Ayaz FA, Hayirlioglu-Ayaz S, Gruz J et al. (2005) Separation, characterization, and quantitation of phenolic acids in a little-known blueberry (Vaccinium arctostaphylos L.) fruit by HPLC-MS. J Agric Food Chem 53(21): 8116-8122. DOI: 10.1021/jf058057y

Azimi P, Ghiasvand R, Feizi A, Hariri M, Abbasi B. (2014) Effects of cinnamon, cardamom, saffron, and ginger consumption on markers of glycemic control, lipid profile, oxidative stress, and inflammation in type 2 diabetes patients. 11(3-4): 258-266. DOI:

10.1900/RDS.2014.11.258

Baell J, Walters MA (2014) Chemistry: Chemical con artists foil drug discovery. Nature 513: 481-483, DOI: $10.1038 / 513481 \mathrm{a}$

Baell JB (2016) Feeling Nature's PAINS: Natural Products, Natural Product Drugs, and Pan Assay Interference Compounds (PAINS). J Nat Prod. 79(3): 616-628, DOI: 10.1021/acs.jnatprod.5b00947

Baiges I, Palmfeldt J, Blade C et al. (2010) Lipogenesis is decreased by grape seed proanthocyanidins according to liver proteomics of rats fed a high fat diet. Mol Cell Proteomics 9(7), 1499-1513. DOI: 10.1074/mcp.M000055-MCP201

Balzer J, Rassaf T, Heiss C et al. (2008) Sustained benefits in vascular function through flavanol-containing cocoa in medicated diabetic patients a double-masked, randomized, controlled trial. J Am Coll Cardiol 51(22): 2141-2149. DOI: 10.1016/j.jacc.2008.01.059

Bang CY \& Choung SY (2014) Enzogenol improves diabetes-related metabolic change in C57BL/KsJ-db/db mice, a model of type 2 diabetes mellitus. J Pharm Pharmacol 66(6), 875885. DOI: 10.1111/jphp.12211 
Basu S, Yoffe P, Hills N, Lustig RH (2013) The relationship of sugar to population-level diabetes prevalence: an econometric analysis of repeated cross-sectional data. PLoS One 8(2): e57873. DOI: 10.1371/journal.pone.0057873

Bailey CJ, Day C (2004) Metformin: its botanical background. Practical Diabetes International 21(3): 115-117, DOI: 10.1002/pdi.606

Bharat D, Cavalcanti RRM, Petersen C, Begaye N, et al. (2017) Blueberry metabolites attenuate lipotoxicity-induced endothelial dysfunction. Molecular Nutrition \& Food Research, 62(2): Art. Nr. 1700601. DOI: 10.1002/mnfr.201700601

Blevins SM, Leyva MJ, Brown J et al. (2007) Effect of cinnamon on glucose and lipid levels in non-insulin-dependent type 2 diabetes. Diabetes Care 30(9): 2236-2237. DOI: $10.2337 / \mathrm{dc} 07-0098$

Brownlee M (2001) Biochemistry and molecular cell biology of diabetic complications. Nature 414(6865): 813-820. DOI: 10.1038/414813a

Cai H, Thomasset SC, P-Berry D et al. (2011) Determination of anthocyanins in the urine of patients with colorectal liver metastases after administration of bilberry extract. Biomed Chromatogr 25(6): 660-663. DOI: 10.1002/bmc.1499

Cao H, Xie YX, Chen XQ (2015) Type 2 diabetes diminishes the benefits of dietary antioxidants: Evidence from the different free radical scavenging potential. Food Chemistry 186: 106-112, DOI: 10.1016/j.foodchem.2014.06.027

Chantre P \& Lairon D (2002) Recent findings of green tea extract AR25 (Exolise) and its activity for the treatment of obesity. Phytomedicine 9(1): 3-8. DOI: 10.1078/0944-711300078

Chen LL, Zhang HH, Zheng J et al. (2011) Resveratrol attenuates high-fat diet-induced insulin resistance by influencing skeletal muscle lipid transport and subsarcolemmal mitochondrial beta-oxidation. Metabolism 60(11), 1598-1609. DOI:

10.1016/j.metabol.2011.04.002

Chen L, Sun P, Wang T et al. (2012) Diverse mechanisms of antidiabetic effects of the different procyanidin oligomer types of two different cinnamon species on $\mathrm{db} / \mathrm{db}$ mice. $\mathrm{J}$ Agric Food Chem 60(36), 9144-9150. DOI: 10.1021/jf3024535

Chen TY, Ferruzzi MG, Wu QL, Simon JE, Talcott ST, Wang J, Ho L, Todd G, Cooper B, Pasinetti GM, Janle EM (2017) Influence of diabetes on plasma pharmacokinetics and brain bioavailability of grape polyphenols and their phase II metabolites in the Zucker diabetic fatty rat. Mol Nutr Food Res. 61(10): Art. Nr. 1700111, DOI:10.1002/mnfr.201700111.

Chi TC, Chen WP, Chi TL et al. (2007) Phosphatidylinositol-3-kinase is involved in the antihyperglycemic effect induced by resveratrol in streptozotocin-induced diabetic rats. Life Sci 80(18), 1713-1720. DOI: 10.1016/j.lfs.2007.02.002

Cho HY, Reddy SP, Yamamoto M, Kleeberger SR (2004) The transcription factor Nrf2 protects against pulmonary fibrosis. FASEB J. 18: 1258-1260. DOI: 10.1096/fj.03-1127fje

Cordero-Herrera I, Martin MA, Bravo L et al. (2013) Cocoa flavonoids improve insulin signalling and modulate glucose production via AKT and AMPK in HepG2 cells. Mol Nutr Food Res 57(6), 974-985. DOI: 10.1002/mnfr.201200500 
Cremonini E, Bettaieb A, Haj FG et al. (2016) (-)-Epicatechin improves insulin sensitivity in high fat diet-fed mice. Arch Biochem Biophys 599, 13-21. DOI: 10.1016/j.abb.2016.03.006

Dange SV, Shende SS, T Rane BT, Tilak AV, Vaidya MU, Limaye MV (2016) An Observational Study of the Antidiabetic Activity of Berberine in Newly Diagnosed Type 2 Diabetes Mellitus Patients. J. Pharm.Biomed. Sci. 6(4): 230-233.

Dans AM, Villarruz MV, Jimeno CA et al. (2007) The effect of Momordica charantia capsule preparation on glycemic control in type 2 diabetes mellitus needs further studies. $\mathbf{J}$ Clin. Epidemiol. 60(6): 554-559. DOI: 10.1016/j.jclinepi.2006.07.009

Deng JY, Hsieh PS, Huang JP et al. (2008) Activation of estrogen receptor is crucial for resveratrol-stimulating muscular glucose uptake via both insulin-dependent and -independent pathways. Diabetes 57(7), 1814-1823. DOI: 10.2337/db07-1750

Deng YX, Shi QZ, Chen B, Zhang XJ, Liu SZ, Qiu XM (2012) Comparative pharmacokinetics of baicalin in normal and the type 2 diabetic rats after oral administration of the Radix scutellariae extract. Fitoterapia 83: 1435-1442. DOI:

10.1016/j.fitote.2012.08.007

Ding Y, Dai X, Zhang Z et al. (2014) Proanthocyanidins protect against early diabetic peripheral neuropathy by modulating endoplasmic reticulum stress. J Nutr Biochem 25(7), 765-772. DOI: 10.1016/j.jnutbio.2014.03.007

Do GM, Jung UJ, Park HJ et al. (2012) Resveratrol ameliorates diabetes-related metabolic changes via activation of AMP-activated protein kinase and its downstream targets in $\mathrm{db} / \mathrm{db}$ mice. Mol Nutr Food Res 56(8), 1282-1291. DOI: 10.1002/mnfr.201200067

Du SL, Xie YX, Chen XQ (2013) Influence of glucose on the human serum albumin-flavone interaction and their antioxidant activity. Mol. BioSyst. 9: 55-60. DOI: 10.1039/c2mb25351h

Eker ME, Aaby K, Budic-Leto I, Brnčić SR, El SN, Karakaya S, Simsek S, Manach C, Wiczkowski W, Pascual-Teresa S (2019) A review of factors affecting anthocyanin bioavailability: possible implications for the inter-individual variability. Foods 9(1): Art. Nr. 2. DOI: $10.3390 /$ foods 9010002

Ezuruike UF, Prieto JM (2014) The use of plants in the traditional management of diabetes in Nigeria: pharmacological and toxicological considerations. J Ethnopharmacol. 155(2): $857-$ 924. DOI: 10.1016/j.jep.2014.05.055

Fournet M, Bonté F, Desmoulière A (2018) Glycation damage: a possible hub for major pathophysiological disorders and aging. Aging Dis. 9(5): 880-900, DOI: 10.14336/AD.2017.1121

Franz MJ, Boucher JL, Rutten-Ramos S, Van Wormer JJ (2015) Lifestyle weight-loss intervention outcomes in overweight and obese adults with type 2 diabetes: a systematic review and meta-analysis of randomized clinical trials. J Acad Nutr Diet. 115(9): 1447-1463. DOI: 10.1016/j.jand.2015.02.031

Fuchs D, Nyakayiru J, Draijer R et al. (2016) Impact of flavonoid-rich black tea and beetroot juice on postprandial peripheral vascular resistance and glucose homeostasis in obese, insulin-resistant men: a randomized controlled trial. Nutr. Metab. (Lond) 13: 34, DOI: 10.1186/s12986-016-0094-X 
Fuhrman B, Rosenblat M, Hayek T et al. (2000) Ginger extract consumption reduces plasma cholesterol, inhibits LDL oxidation and attenuates development of atherosclerosis in atherosclerotic, apolipoprotein E-deficient mice. J Nutr 130(5): 1124-1131. DOI: $10.1093 / \mathrm{jn} / 130.5 .1124$

Fukuda T, Fukui M, Tanaka M, Senmaru T, Iwase H, Yamazaki M, Aoi W, Inui T, Nakamura N, Marunaka Y (2015) Effect of Brazilian green propolis in patients with type 2 diabetes: A double-blind randomized placebo-controlled study. Biomed Rep. 3(3): 355-360, DOI: $10.3892 / b r .2015 .436$

Garbin U, Fratta Pasini A, Stranieri C, Cominacini M, Pasini A, et al. (2009) Cigarette smoking blocks the protective expression of Nrf2/ARE pathway in peripheral mononuclear cells of young heavy smokers favouring inflammation. PLoS ONE 4: e8225. DOI: 10.1371/journal.pone.0008225

Gillis CN (1997) Panax ginseng pharmacology: a nitric oxide link? Biochem Pharmacol 54(1): 1-8. DOI: 10.1016/s0006-2952(97)00193-7

Gin H, Rigalleau V, Caubet O et al. (1999) Effects of red wine, tannic acid, or ethanol on glucose tolerance in non-insulin-dependent diabetic patients and on starch digestibility in vitro. Metabolism 48(9), 1179-1183. DOI: 10.1016/s0026-0495(99)90135-x

Goh KP, Lee HY, Lau DP et al. (2014) Effects of resveratrol in patients with type 2 diabetes mellitus on skeletal muscle SIRT1 expression and energy expenditure. Int J Sport Nutr Exerc Metab 24(1), 2-13. DOI: 10.1123/ijsnem.2013-0045

Gonzalez JS, Tanenbaum ML, Commissariat PV (2016) Psychosocial factors in medication adherence and diabetes self-management: Implications for research and practice. Am Psychol. 71(7): 539-551. DOI: 10.1037/a0040388

Govindaraj J \& Sorimuthu Pillai S (2015) Rosmarinic acid modulates the antioxidant status and protects pancreatic tissues from glucolipotoxicity mediated oxidative stress in high-fat diet: streptozotocin-induced diabetic rats. Mol Cell Biochem 404(1-2), 143-159. DOI: $10.1007 / \mathrm{s} 11010-015-2374-6$

Guo H, Guo J, Jiang X et al. (2012) Cyanidin-3-O-beta-glucoside, a typical anthocyanin, exhibits antilipolytic effects in 3T3-L1 adipocytes during hyperglycemia: involvement of FoxO1-mediated transcription of adipose triglyceride lipase. Food Chem Toxicol 50(9), 3040-3047. DOI: 10.1016/j.fct.2012.06.015

Hajiaghaalipour F, Khalilpourfarshbafi M, Arya A (2015) Modulation of glucose transporter protein by dietary flavonoids in type 2 diabetes mellitus. Int. J. Biol. Sci. 11(5): 508-524, DOI: 10.7150/ijbs.11241

He X, Ma Q (2012) Disruption of Nrf2 synergizes with high glucose to cause heightened myocardial oxidative stress and severe cardiomyopathy in diabetic mice. J Diabetes Metab. Suppl 7. pii: 002, DOI: 10.4172/2155-6156.S7-002

Herman WH, Edelstein SL, Ratner RE, et al. (2013) Effectiveness and cost-effectiveness of diabetes prevention among adherent participants. Am J Manag Care. 19(3): 194-202.

Hoggard N, Cruickshank M, Moar KM et al. (2013) A single supplement of a standardised bilberry (Vaccinium myrtillus L.) extract (36\% wet weight anthocyanins) modifies glycaemic 
response in individuals with type 2 diabetes controlled by diet and lifestyle. J. Nutr. Sci. 2: Art ID e22. DOI: 10.1017/jns.2013.16

Hollman PC, Cassidy A, Comte B et al. (2011) The biological relevance of direct antioxidant effects of polyphenols for cardiovascular health in humans is not established. J Nutr 141(5): 989S-1009S. DOI: 10.3945/jn.110.131490

Hosoyama H, Sugimoto A, Suzuki Y et al. (2003) Isolation and quantitative analysis of the alpha-amylase inhibitor in Lagerstroemia speciosa (L.) Pers. (Banaba). Yakugaku Zasshi 123(7), 599-605. DOI: 10.1248/yakushi.123.599

Hsu JH, Wu YC, Liu IM et al. (2006) Release of acetylcholine to raise insulin secretion in Wistar rats by oleanolic acid, one of the active principles contained in Cornus officinalis. Neurosci Lett 404(1-2): 112-116. DOI: 10.1016/j.neulet.2006.05.025

Huyen VTT, Phan DV, Thang P, Hoa NK, Ostenson CG (2010) Antidiabetic effect of Gynostemma pentaphyllum tea in randomly assigned type 2 diabetic patients. Horm. Metab. Res. 42(5): 353-357. DOI: 10.1055/s-0030-1248298

Huyen VTT, Phan DV, Thang P, Ky PT, Hoa NK, Ostenson CG (2012) Antidiabetic Effects of add-on Gynostemma pentaphyllum extract therapy with sulfonylureas in type 2 diabetic patients. Evid. Based Complement. Alternat. Med.: Art. Nr. 452313, DOI: $10.1155 / 2012 / 452313$

Huyen VTT, Phan DV, Thang P, Hoa NK, Östenson CG (2013) Gynostemma pentaphyllum tea improves insulin sensitivity in type 2 diabetic patients. J. Nutr. Metab.: Art. Nr. 765383, DOI: $10.1155 / 2013 / 765383$

Ingólfsson HI, Thakur P, Herold KF, et al. (2014) Phytochemicals perturb membranes and promiscuously alter protein function. ACS Chem Biol. 9(8): 1788-1798, DOI: $10.1021 / \mathrm{cb} 500086 \mathrm{e}$

Jayaprakasam B, Olson LK, Schutzki RE et al. (2006) Amelioration of obesity and glucose intolerance in high-fat-fed C57BL/6 mice by anthocyanins and ursolic acid in Cornelian cherry (Cornus mas). J Agric Food Chem 54(1): 243-248. DOI: 10.1021/jf0520342

Jayaprakasam B, Vareed SK, Olson LK et al. (2005) Insulin secretion by bioactive anthocyanins and anthocyanidins present in fruits. J Agric Food Chem 53(1): 28-31. DOI: 10.1021/jf049018+

Jin T, Song Z, Weng J et al. (2018) Curcumin and other dietary polyphenols: potential mechanisms of metabolic actions and therapy for diabetes and obesity. Am J Physiol Endocrinol Metab 314(3), E201-E205. DOI: 10.1152/ajpendo.00285.2017

John AJ, Cherian R, Subhash HS et al. (2003) Evaluation of the efficacy of bitter gourd (Momordica charantia) as an oral hypoglycemic agent--a randomized controlled clinical trial. Indian J. Physio.1 Pharmacol. 47(3): 363-365.

Johnson DA, Amirahmadi S, Ward C, Fabry Z, Johnson JA (2010) The absence of the proantioxidant transcription factor Nrf2 exacerbates experimental autoimmune encephalomyelitis. Toxicol. Sci. 114: 237-246. DOI: 10.1093/toxsci/kfp274 
Johnson MH, de Mejia EG, Fan J et al. (2013) Anthocyanins and proanthocyanidins from blueberry-blackberry fermented beverages inhibit markers of inflammation in macrophages and carbohydrate-utilizing enzymes in vitro. Mol Nutr Food Res 57(7), 1182-1197. DOI: 10.1002/mnfr.201200678

Johnson MH, Wallig M, Luna Vital DA et al. (2016) Alcohol-free fermented blueberryblackberry beverage phenolic extract attenuates diet-induced obesity and blood glucose in C57BL/6J mice. J Nutr Biochem 31, 45-59. DOI: 10.1016/j.jnutbio.2015.12.013

Jung EH, Kim SR, Hwang IK et al. (2007) Hypoglycemic effects of a phenolic acid fraction of rice bran and ferulic acid in C57BL/KsJ-db/db mice. J Agric Food Chem 55(24), 98009804. DOI: $10.1021 / \mathrm{jf0714463}$

Kasetti RB, Nabi SA, Swapna S et al. (2012) Cinnamic acid as one of the antidiabetic active principle(s) from the seeds of Syzygium alternifolium. Food Chem Toxicol 50(5), 1425-1431. DOI: 10.1016/j.fct.2012.02.003

Kato CG, Goncalves GA, Peralta RA et al. (2017) Inhibition of $\alpha$-amylases by condensed and hydrolysable tannins: focus on kinetics and hypoglycemic actions. Enzyme Res 2017, 5724902. DOI: $10.1155 / 2017 / 5724902$

Khan A, Safdar M, Ali Khan MM et al. (2003) Cinnamon improves glucose and lipids of people with type 2 diabetes. Diabetes Care 26(12): 3215-3218. DOI:

10.2337/diacare.26.12.3215

Khandouzi N, Shidfar F, Rajab A et al. (2015) The effects of ginger on fasting blood sugar, hemoglobin A1c, apolipoprotein B, apolipoprotein a-I and malondialdehyde in type 2 diabetic patients. Iran J Pharm Res 14(1): 131-140.

Kianbakht S, Abasi B, Dabaghian FH (2013) Anti-hyperglycemic effect of Vaccinium arctostaphylos in type 2 diabetic patients: a randomized controlled trial. Forsch.

Komplementmed. 20(1): 17-22. DOI: 10.1159/000346607

Kim HY, Kim K (2003) Protein glycation inhibitory and antioxidative activities of some plant extracts in vitro. J Agric Food Chem. 51(6): 1586-1591, DOI: 10.1021/jf020850t

Kim JJ, Tan Y, Xiao L et al. (2013) Green tea polyphenol epigallocatechin-3-gallate enhance glycogen synthesis and inhibit lipogenesis in hepatocytes. Biomed Res Int 2013, 920128. DOI: $10.1155 / 2013 / 920128$

Kobayashi Y, Suzuki M, Satsu H et al. (2000) Green tea polyphenols inhibit the sodiumdependent glucose transporter of intestinal epithelial cells by a competitive mechanism. J Agric Food Chem 48(11), 5618-5623. DOI: 10.1021/jf0006832

Kumar S, Narwal S, Kumar V et al. (2011) $\alpha$-Glucosidase inhibitors from plants: A natural approach to treat diabetes. Pharmacogn Rev 5(9): 19-29. DOI: 10.4103/0973-7847.79096

Kurimoto Y, Shibayama Y, Inoue S et al. (2013) Black soybean seed coat extract ameliorates hyperglycemia and insulin sensitivity via the activation of AMP-activated protein kinase in diabetic mice. J Agric Food Chem 61(23), 5558-5564. DOI: 10.1021/jf401190y 
Lan J, Zhao Y, Dong F, Yan Z, Zheng W, Fan J, Sun G (2015) Meta-analysis of the effect and safety of berberine in the treatment of type 2 diabetes mellitus, hyperlipemia and hypertension. J. Ethnopharmacol. 161: 69-81. DOI: 10.1016/j.jep.2014.09.049

Lazavi F, Mirmiran P, Sohrab G et al. (2018) The barberry juice effects on metabolic factors and oxidative stress in patients with type 2 diabetes: A randomized clinical trial. Complement. Ther. Clin. Pract. 31, 170-174. DOI: 10.1016/j.ctcp.2018.01.009

Lee DY, Chung HJ, Choi YH, Lee U, Kim SH, Lee I, Lee MG (2009) Pharmacokinetics of ipriflavone and its two metabolites, M1 and M5, after the intravenous and oral administration of ipriflavone to rat model of diabetes mellitus induced by streptozotocin. Eur. J. Pharmaceut. Sci. 38(5): 465-471. DOI: 10.1016/j.ejps.2009.09.008

Li F, Gao C, Yan P et al. (2018a) EGCG reduces obesity and white adipose tissue gain partly through ampk activation in mice. Front Pharmacol 9, 1366. DOI: 10.3389/fphar.2018.01366

Li X, Li S, Chen M et al. (2018b) (-)-Epigallocatechin-3-gallate (EGCG) inhibits starch digestion and improves glucose homeostasis through direct or indirect activation of PXR/CAR-mediated phase II metabolism in diabetic mice. Food Funct 9(9), 4651-4663. DOI: $10.1039 / \mathrm{c} 8$ fo01293h

Lee YA, Cho EJ, Tanaka T et al. (2007) Inhibitory activities of proanthocyanidins from persimmon against oxidative stress and digestive enzymes related to diabetes. J Nutr Sci Vitaminol (Tokyo) 53(3), 287-292. DOI: 10.3177/jnsv.53.287

Li W, Khor TO, Xu C, Shen G, Jeong WS, et al. (2008) Activation of Nrf2-antioxidant signaling attenuates NFkB-inflammatory response and elicits apoptosis. Biochem. Pharmacol. 76: 1485-1489. DOI: 10.1016/j.bcp.2008.07.017

Liu D, Zhen W, Yang Z, Carter JD, Si H, Reynolds KA (2006) Genistein acutely stimulates insulin secretion in pancreatic beta-cells through a cAMP-dependent protein kinase pathway. Diabetes 55(4):1043-1050, DOI: 10.2337/diabetes.55.04.06.db05-1089

Liu X, Kim JK, Li Y et al. (2005) Tannic acid stimulates glucose transport and inhibits adipocyte differentiation in 3T3-L1 cells. J Nutr 135(2), 165-171. DOI: 10.1093/jn/135.2.165

Lu Z, Jia Q, Wang R et al. (2011) Hypoglycemic activities of A- and B-type procyanidin oligomer-rich extracts from different cinnamon barks. Phytomedicine 18(4), 298-302. DOI: 10.1016/j.phymed.2010.08.008

Lundberg JO, Feelisch M, Bjorne $\mathrm{H}$ et al. (2006) Cardioprotective effects of vegetables: is nitrate the answer? Nitric Oxide 15(4): 359-362. DOI: 10.1016/j.niox.2006.01.013

Lebda MA, Taha NM, Korshom A, Mandour AWA, El-Morshedy AM (2012) Biochemical effect of ginger on some blood and liver parameters in male New Zealand rabbits. J. Anim. Feed Res. 2(2): 197-202.

Ma Q, Kinneer K, Ye J, Chen BJ (2003) Inhibition of nuclear factor $\kappa$ B by phenolic antioxidants: interplay between antioxidant signaling and inflammatory cytokine expression. Mol. Pharmacol. 64: 211-219. DOI: 10.1124/mol.64.2.211

Ma Q (2013) Role of nrf2 in oxidative stress and toxicity. Annu Rev Pharmacol Toxicol 53, 401-426. DOI: 10.1146/annurev-pharmtox-011112-140320 
Ma SW, Benzie IF, Chu TT et al. (2008) Effect of Panax ginseng supplementation on biomarkers of glucose tolerance, antioxidant status and oxidative stress in type 2 diabetic subjects: results of a placebo-controlled human intervention trial. Diabetes Obes Metab 10(11): 1125-1127. DOI: 10.1111/j.1463-1326.2008.00858.x

Mackenzie T, Leary L, Brooks WB (2007) The effect of an extract of green and black tea on glucose control in adults with type 2 diabetes mellitus: double-blind randomized study. Metabolism 56(10): 1340-1344. DOI: 10.1016/j.metabol.2007.05.018

Mahmoud F, Al-Ozairi E, Haines D et al. (2016) Effect of Diabetea tea consumption on inflammatory cytokines and metabolic biomarkers in type 2 diabetes patients. J. Ethnopharmacol. 194, 1069-1077. DOI: 10.1016/j.jep.2016.10.073

Maithili Karpaga Selvi N, Sridhar MG, Swaminathan RP et al. (2015) Efficacy of Turmeric as Adjuvant Therapy in Type 2 Diabetic Patients. Indian J. Clin. Biochem. 30(2): 180-186. DOI: $10.1007 / \mathrm{s} 12291-014-0436-2$

Mang B, Wolters M, Schmitt B et al. (2006) Effects of a cinnamon extract on plasma glucose, $\mathrm{HbA}$, and serum lipids in diabetes mellitus type 2. Eur J Clin Invest 36(5): 340-344. DOI: 10.1111/j.1365-2362.2006.01629.x

Matsui T, Tanaka T, Tamura S et al. (2007) $\alpha$-Glucosidase inhibitory profile of catechins and theaflavins. J Agric Food Chem 55(1), 99-105. DOI: 10.1021/jf0627672

Matzinger M, Fischhuber K, Heiss EH (2018) Activation of Nrf2 signaling by natural products-can it alleviate diabetes? Biotechnol Adv. 36(6): 1738-1767, DOI:

10.1016/j.biotechadv.2017.12.015

McPherson JD, Shilton BH, Walton DJ (1988) Role of fructose in glycation and cross-linking of proteins. Biochemistry 27(6): 1901-1907, DOI: 10.1021/bi00406a016

Medina-Remón A, Kirwan R, Lamuela-Raventós RM, Estruch R. (2017) Dietary patterns and the risk of obesity, type 2 diabetes mellitus, cardiovascular diseases, asthma, and neurodegenerative diseases. Crit Rev Food Sci Nutr. 58(2): 262-296. DOI:

10.1080/10408398.2016.1158690

Mellor DD, Madden LA, Smith KA et al. (2013) High-polyphenol chocolate reduces endothelial dysfunction and oxidative stress during acute transient hyperglycaemia in Type 2 diabetes: a pilot randomized controlled trial. Diabet Med 30(4): 478-483. DOI:

10.1111/dme. 12030

Mi Y, Zhang W, Tian H et al. (2018) EGCG evokes Nrf2 nuclear translocation and dampens PTP1B expression to ameliorate metabolic misalignment under insulin resistance condition. Food Funct 9(3), 1510-1523. DOI: 10.1039/c7fo01554b

Moazen S, Amani R, Homayouni Rad A et al. (2013) Effects of freeze-dried strawberry supplementation on metabolic biomarkers of atherosclerosis in subjects with type 2 diabetes: a randomized double-blind controlled trial. Ann Nutr. Metab. 63(3): 256-264. DOI: $10.1159 / 000356053$

Moazezi Z \& Qujeq D (2014) Berberis fruit extract and biochemical parameters in patients with type II diabetes. Jundishapur J. Nat. Pharm. Prod. 9(2): Art. ID e13490. DOI: 10.17795/jjnpp-13490 
Mousavi A, Vafa M, Neyestani T, Khamseh M, Hoseini F (2013) The effects of green tea consumption on metabolic and anthropometric indices in patients with Type 2 diabetes. J. Res. Med. Sci. 18(12): 1080-1086

Mozaffari-Khosravi H, Ahadi Z, Fallah Tafti M (2014a) The effect of green tea versus sour tea on insulin resistance, lipids profiles and oxidative stress in patients with type 2 diabetes mellitus: a randomized clinical trial. Iran J. Med. Sci. 39(5): 424-432.

Mozaffari-Khosravi H, Talaei B, Jalali BA, Najarzadeh A, Mozayan MR. (2014b) The effect of ginger powder supplementation on insulin resistance and glycemic indices in patients with type 2 diabetes: a randomized, double-blind, placebo-controlled trial. Complement. Ther. Med. 22(1): 9-16. DOI: 10.1016/j.ctim.2013.12.017

Nagao T, Hase T, Tokimitsu I (2007) A green tea extract high in catechins reduces body fat and cardiovascular risks in humans. Obesity 15(6): 1473-1483. DOI: $10.1038 /$ oby.2007.176

Nagao T, Meguro S, Hase T et al. (2009) A catechin-rich beverage improves obesity and blood glucose control in patients with type 2 diabetes. Obesity 17(2): 310-317. DOI: 10.1038/oby.2008.505

Ohnishi M, Matuo T, Tsuno T et al. (2004) Antioxidant activity and hypoglycemic effect of ferulic acid in STZ-induced diabetic mice and KK-Ay mice. Biofactors 21(1-4), 315-319. DOI: $10.1002 /$ biof.552210161

Ong KC \& Khoo HE (2000) Effects of myricetin on glycemia and glycogen metabolism in diabetic rats. Life Sci 67(14): 1695-1705. DOI: 10.1016/s0024-3205(00)00758-X

Palsamy P \& Subramanian S (2010) Ameliorative potential of resveratrol on proinflammatory cytokines, hyperglycemia mediated oxidative stress, and pancreatic betacell dysfunction in streptozotocin-nicotinamide-induced diabetic rats. J Cell Physiol 224(2), 423-432. DOI: $10.1002 /$ jcp. 22138

Pei K, Ou J, Huang J et al. (2016) p-Coumaric acid and its conjugates: dietary sources, pharmacokinetic properties and biological activities. J Sci Food Agric 96(9), 2952-2962. DOI: $10.1002 /$ jsfa.7578

Peter EL, Kasali FM, Deyno S, et al. (2019) Momordica charantia L. lowers elevated glycaemia in type 2 diabetes mellitus patients: Systematic review and meta-analysis. J Ethnopharmacol. 231: 311-324. DOI: 10.1016/j.jep.2018.10.033

Peyroux J, Sternberg M (2006) Advanced glycation endproducts (AGEs): Pharmacological inhibition in diabetes. Pathol Biol (Paris) 54(7): 405-419, DOI: 10.1016/j.patbio.2006.07.006

Pinna C, Morazzoni P, Sala A (2017) Proanthocyanidins from Vitis vinifera inhibit oxidative stress-induced vascular impairment in pulmonary arteries from diabetic rats. Phytomedicine 25: 39-44. DOI: 10.1016/j.phymed.2016.12.015

Pivari F, Mingione A, Brasacchio C et al. (2019) Curcumin and Type 2 Diabetes Mellitus: Prevention and Treatment. Nutrients 11(8), 1837. DOI: 10.3390/nu11081837.

Rangasamy T, Cho CY, Thimmulappa RK, Zhen L, Srisuma SS, et al. (2004) Genetic ablation of Nrf2 enhances susceptibility to cigarette smoke-induced emphysema in mice. J. Clin. Investig. 114: 1248-1259. DOI: 10.1172/JCI21146 
Rangasamy T, Guo J, Mitzner WA, Roman J, Singh A, et al. (2005) Disruption of Nrf2 enhances susceptibility to severe airway inflammation and asthma in mice. J. Exp. Med. 202: 47-59. DOI: $10.1084 /$ jem.20050538

Ras RT, Zock PL, Draijer R (2011) Tea consumption enhances endothelial-dependent vasodilation; a meta-analysis. PLoS One 6(3): Art. Nr. e16974. DOI:

10.1371/journal.pone.0016974

Rashid K, Chowdhury S, Ghosh S et al. (2017) Curcumin attenuates oxidative stress induced $\mathrm{NF} \kappa \mathrm{B}$ mediated inflammation and endoplasmic reticulum dependent apoptosis of splenocytes in diabetes. Biochem Pharmacol 143, 140-155. DOI: 10.1016/j.bcp.2017.07.009

Roy D, Perreault M, Marette A (1998) Insulin stimulation of glucose uptake in skeletal muscles and adipose tissues in vivo is NO dependent. Am J Physiol 274(4): 692-699. DOI: 10.1152/ajpendo.1998.274.4.E692

Roy M, Sen S, Chakraborti AS (2008) Action of pelargonidin on hyperglycemia and oxidative damage in diabetic rats: implication for glycation-induced hemoglobin modification. Life Sci 82(21-22), 1102-1110. DOI: 10.1016/j.lfs.2008.03.011

Ryu OH, Lee J, Lee KW et al. (2006) Effects of green tea consumption on inflammation, insulin resistance and pulse wave velocity in type 2 diabetes patients. Diabetes Res Clin Pract 71(3): 356-358. DOI: 10.1016/j.diabres.2005.08.001

Santangelo C, Filesi C, Vari R et al. (2016) Consumption of extra-virgin olive oil rich in phenolic compounds improves metabolic control in patients with type 2 diabetes mellitus: a possible involvement of reduced levels of circulating visfatin. J Endocrinol. Invest. 39(11): 1295-1301. DOI: 10.1007/s40618-016-0506-9

Sarwar N, Gao P, Seshasai SRK, et al. (2010a) Diabetes mellitus, fasting blood glucose concentration, and risk of vascular disease: a collaborative meta-analysis of 102 prospective studies. The Lancet. 375(9733): 2215-22. DOI: 10.1016/S0140-6736(10)60484-9

Sarwar N, Danesh J. Triglyceride-mediated pathways and coronary heart disease Reply. The Lancet 376(9745): 957-958. DOI: 10.1016/S0140-6736(10)61450-X

Schäfer A \& Högger P (2007) Oligomeric procyanidins of French maritime pine bark extract (Pycnogenol) effectively inhibit $\alpha$-glucosidase. Diabetes Res Clin Pract 77(1): 41-46. DOI: 10.1016/j.diabres.2006.10.011

Schell J, Betts NM, Foster M et al. (2017) Cranberries improve postprandial glucose excursions in type 2 diabetes. Food Funct 8(9): 3083-3090. DOI: 10.1039/c7fo00900c

Schell J, Betts NM, Lyons TJ et al. (2019) Raspberries Improve Postprandial Glucose and Acute and Chronic Inflammation in Adults with Type 2 Diabetes. Ann Nutr Metab 74(2): 165-174. DOI: 10.1159/000497226

Schwingshackl L, Hoffmann G, Lampousi AM, et al., (2017) Food groups and risk of type 2 diabetes mellitus: a systematic review and meta-analysis of prospective studies. Eur J Epidemiol. 32(5): 363-375. DOI: 10.1007/s10654-017-0246-y 
Serrano J, Puupponen-Pimiä R, Dauer A et al. (2009) Tannins: current knowledge of food sources, intake, bioavailability and biological effects. Mol. Nutr. Food Res. 53: S310-S329. DOI: $10.1002 / \mathrm{mnfr} .200900039$

Seshasai SRK, Kaptoge S, Thompson A, et al. (2011) Diabetes mellitus, fasting glucose, and risk of cause-specific death. N Engl J Med. 364(9): 829-841. DOI: 10.1056/NEJMoa1008862

Shidfar F, Ebrahimi SS, Hosseini S et al. (2012a) The effects of Berberis vulgaris fruit extract on serum lipoproteins, apoB, apoA-I, homocysteine, glycemic control and total antioxidant capacity in type 2 diabetic patients. Iran J Pharm Res 11(2): 643-652.

Shidfar F, Heydari I, Hajimiresmaiel SJ et al. (2012b) The effects of cranberry juice on serum glucose, apoB, apoA-I, Lp(a), and paraoxonase-1 activity in type 2 diabetic male patients. $\mathbf{J}$ Res Med Sci 17(4): 355-360.

Shimizu M, Kobayashi Y, Suzuki M et al. (2000) Regulation of intestinal glucose transport by tea catechins. Biofactors 13(1-4), 61-65. DOI: 10.1002/biof.5520130111

Solinas G \& Becattini B (2016) JNK at the crossroad of obesity, insulin resistance, and cell stress response. Mol Metab 6(2), 174-184. DOI: 10.1016/j.molmet.2016.12.001

Soltani R, Gorji A, Asgary S et al. (2015) Evaluation of the effects of Cornus mas L. fruit extract on glycemic control and insulin level in type 2 diabetic adult patients: a randomized double-blind placebo-controlled clinical trial. Evid. Based Complement. Alternat. Med. 2015, 740954. DOI: $10.1155 / 2015 / 740954$.

Son MJ, Rico CW, Nam SH et al. (2011) Effect of oryzanol and ferulic acid on the glucose metabolism of mice fed with a high-fat diet. J Food Sci 76(1), H7-H10. DOI: 10.1111/j.17503841.2010.01907.x

Spinas GA, Laffranchi R, Francoys I et al. (1998) The early phase of glucose-stimulated insulin secretion requires nitric oxide. Diabetologia 41(3): 292-299. DOI:

$10.1007 / \mathrm{s} 001250050906$

Sun C, Zhao C, Çapanoğlu Güven E, Paoli P, Simal-Gandara J, Ramkumar KM, Wang S, Buleu F, Pah A, Turi V, Damian G, Dragan S, Tomas M, Khan W, Wang M, Delmas D, Portillo MP, Dar P, Chen L, Xiao J (2020) Dietary polyphenols as antidiabetic agents: Advances and opportunities. Food Frontiers 1(1): 18-44. DOI: 10.1002/fft2.15

Sun X, Du M, Navarre DA et al. (2018) Purple Potato Extract Promotes Intestinal Epithelial Differentiation and Barrier Function by Activating AMP-Activated Protein Kinase. Mol Nutr Food Res 62(4): Art. Nr 1700536. DOI: 10.1002/mnfr.201700536

Szeto YT, Tomlinson B, Benzie IF (2002) Total antioxidant and ascorbic acid content of fresh fruits and vegetables: implications for dietary planning and food preservation. Br J Nutr 87(1): 55-59. DOI: 10.1079/BJN2001483

Takikawa M, Inoue S, Horio F et al. (2010) Dietary anthocyanin-rich bilberry extract ameliorates hyperglycemia and insulin sensitivity via activation of AMP-activated protein kinase in diabetic mice. J Nutr 140(3), 527-533. DOI: 10.3945/jn.109.118216

Tan Z, Zhou LJ, Mu PW et al. (2012) Caveolin-3 is involved in the protection of resveratrol against high-fat-diet-induced insulin resistance by promoting GLUT4 translocation to the plasma membrane in skeletal muscle of ovariectomized rats. J Nutr Biochem 23(12), 17161724. DOI: 10.1016/j.jnutbio.2011.12.003 
Tanaka Y, Atsumi Y, Matsuoka K et al. (2001) Usefulness of stable HbA(1c) for supportive marker to diagnose diabetes mellitus in Japanese subjects. Diabetes Res Clin Pract 53(1): 4145. DOI: $10.1016 / \mathrm{S} 0168-8227(01) 00226-1$

Teoh SL, Das S (2018) Phytochemicals and their effective role in the treatment of diabetes mellitus: a short review. Phytochem Rev 17: 1111-1128. DOI: 10.1007/s11101-018-9575-z

Tsuda T, Horio F, Osawa T (1999) Absorption and metabolism of cyanidin 3-O- $\beta-D-$ glucoside in rats. FEBS Lett 449(2-3), 179-182. DOI: 10.1016/s0014-5793(99)00407-x

Tsuneki H, Ishizuka M, Terasawa M et al. (2004) Effect of green tea on blood glucose levels and serum proteomic patterns in diabetic $(\mathrm{db} / \mathrm{db})$ mice and on glucose metabolism in healthy humans. BMC Pharmacol 4, 18-18. DOI: 10.1186/1471-2210-4-18

Ueda M, Furuyashiki T, Yamada K et al. (2010) Tea catechins modulate the glucose transport system in 3T3-L1 adipocytes. Food Funct 1(2), 167-173. DOI: 10.1039/c0fo00105h

USDA (2014) USDA Database for the Flavonoid Content of Selected Foods, Release 3.1

Dec. 2013 with revision May 2014, https://www.ars.usda.gov/ARSUserFiles/80400525/Data/Flav/Flav_R03-1.pdf

van Dijk AE, Olthof MR, Meeuse JC, Seebus E, Heine RJ, van Dam RM (2009) Acute effects of decaffeinated coffee and the major coffee components chlorogenic acid and trigonelline on glucose tolerance. Diabetes Care 32(6): 1023-1025, DOI: 10.2337/dc09-0207

Vazquez-Flores AA, Martinez-Gonzalez AI, Alvarez-Parrilla E et al. (2018)

Proanthocyanidins with a low degree of polymerization are good inhibitors of digestive enzymes because of their ability to form specific interactions: a hypothesis. J Food Sci 83(12), 2895-2902. DOI: 10.1111/1750-3841.14386

Vuksan V, Sievenpiper JL, Koo VY et al. (2000a) American ginseng (Panax quinquefolius L) reduces postprandial glycemia in nondiabetic subjects and subjects with type 2 diabetes mellitus. Arch. Intern. Med. 160(7): 1009-1013, DOI: 10.1001/archinte.160.7.1009

Vuksan V, Stavro MP, Sievenpiper JL et al. (2000b) Similar postprandial glycemic reductions with escalation of dose and administration time of American ginseng in type 2 diabetes. Diabetes Care 23(9): 1221-1226, DOI: 10.2337/diacare.23.9.1221

Vuksan V, Sung MK, Sievenpiper JL et al. (2008) Korean red ginseng (Panax ginseng) improves glucose and insulin regulation in well-controlled, type 2 diabetes: results of a randomized, double-blind, placebo-controlled study of efficacy and safety. Nutr Metab Cardiovasc. Dis. 18(1): 46-56, DOI: 10.1016/j.numecd.2006.04.003

Wang YL, Zhao Y, Yang F, Yuan YM, Wang H, Xiao JB (2012) Influences of glucose on the dietary hydroxyflavonoid-plasma protein interaction. J. Agric. Food Chem. 60: 12116-12221, DOI: $10.1021 /$ jf $303094 \mathrm{e}$

Welsh KJ, Kirkman MS, Sacks DB (2016) Role of Glycated Proteins in the Diagnosis and Management of Diabetes: Research Gaps and Future Directions. Diabetes Care 39(8): 12991306, DOI: $10.2337 / \mathrm{dc} 15-2727$

Williams R, Colagiuri S, Almutairi R, et al. (2019) IDF Diabetes Atlas 9th edition. International Diabetes Federation ISBN: 978-2-930229-87-4 
Wilson T, Luebke JL, Morcomb EF et al. (2010) Glycemic responses to sweetened dried and raw cranberries in humans with type 2 diabetes. J Food Sci 75(8): 218. DOI: 10.1111/j.17503841.2010.01800.x

Xiao J, Ni X, Kai G, Chen X (2013a): A review on structure-activity relationship of dietary polyphenols inhibiting $\alpha$-amylase. Critical Reviews in Food Science and Nutrition, 53(5): 497-506, DOI: 10.1080/10408398.2010.548108

Xiao J, Kai G, Yamamoto K, Chen X (2013b) Advance in dietary polyphenols as $\alpha$ glucosidases inhibitors: a review on structure-activity relationship aspect. Critical Reviews in Food Science and Nutrition 53(8): 818-836, DOI: 10.1080/10408398.2011.561379

Xiao JB, Högger P (2014) Influence of diabetes on the pharmacokinetic behavior of natural polyphenols. Current Drug Metabolism 15(1): 23-29, DOI:

$10.2174 / 1389200214666131210142614$

Xie YX, Xiao JB, Kai GY, Chen XQ (2012) Glycation of plasma proteins in type II diabetes lowers the non-covalent interaction affinities for dietary polyphenols. Integr. Biol. 4(5): 502507. DOI: $10.1039 / \mathrm{c} 2 \mathrm{ib} 00185 \mathrm{c}$

Xie Y, Chen X (2013) Structures required of polyphenols for inhibiting advanced glycation end products formation. Curr Drug Metab. 14(4): 414-431, DOI:

$10.2174 / 1389200211314040005$

Yamashita Y, Wang L, Nanba F et al. (2016) Procyanidin Promotes Translocation of Glucose Transporter 4 in Muscle of Mice through Activation of Insulin and AMPK Signaling Pathways. PLoS One 11(9), e0161704. DOI: 10.1371/journal.pone.0161704

Yan F, Zheng X (2017) Anthocyanin-rich mulberry fruit improves insulin resistance and protects hepatocytes against oxidative stress during hyperglycemia by regulating AMPK/ACC/mTOR pathway. J. Func. Foods 30: 270-281. DOI: 10.1016/j.jff.2017.01.027

Yang K, Chan CB (2017) Proposed mechanisms of the effects of proanthocyanidins on glucose homeostasis. Nutr Rev 75(8), 642-657. DOI: 10.1093/nutrit/nux028

Yeh WJ, Yang HY, Pai MH, Wu CH, Chen JR (2017a) Long-term administration of advanced glycation end-product stimulates the activation of NLRP3 inflammasome and sparking the development of renal injury. J Nutr Biochem. 39: 68-76, DOI:

10.1016/j.jnutbio.2016.09.014

Yeh WJ, Hsia SM, Lee WH, Wu CH (2017b) Polyphenols with antiglycation activity and mechanisms of action: A review of recent findings. J Food Drug Anal. 25(1) :84-92. DOI: 10.1016/j.jfda.2016.10.017

Yin J, Xing H, Ye J (2008) Efficacy of berberine in patients with type 2 diabetes mellitus. Metabolism 57(5): 712-717. DOI: 10.1016/j.metabol.2008.01.013

Zaccardi F, Webb DR, Yates T, Davies MJ (2016) Pathophysiology of type 1 and type 2 diabetes mellitus: a 90-year perspective. Postgrad Med J. 92(1084): 63-9. DOI:

10.1136/postgradmedj-2015-133281 
Zha W, Bai Y, Xu L et al. (2018) Curcumin attenuates testicular injury in rats with streptozotocin-induced diabetes. Biomed Res Int 2018, 7468019. DOI:

$10.1155 / 2018 / 7468019$

Zhang HJ, Ji BP, Chen G et al. (2009) A combination of grape seed-derived procyanidins and gypenosides alleviates insulin resistance in mice and HepG2 cells. J. Food Sci. 74(1): H1-H7. DOI: $10.1111 / \mathrm{j} .1750-3841.2008 .00976 . x$

Zhang J \& Kashket S (1998) Inhibition of salivary amylase by black and green teas and their effects on the intraoral hydrolysis of starch. Caries Res 32(3): 233-238. DOI: $10.1159 / 000016458$

Zhang W, Hong D, Zhou Y et al. (2006) Ursolic acid and its derivative inhibit protein tyrosine phosphatase $1 \mathrm{~B}$, enhancing insulin receptor phosphorylation and stimulating glucose uptake. Biochim Biophys Acta 1760(10): 1505-1512. DOI: 10.1016/j.bbagen.2006.05.009

Zhang Y, Li X, Zou D et al. (2008) Treatment of type 2 diabetes and dyslipidemia with the natural plant alkaloid berberine. J Clin Endocrinol Metab 93(7): 2559-2565. DOI: 10.1210/jc.2007-2404

Zhong L, Furne JK, Levitt MD (2006) An extract of black, green, and mulberry teas causes malabsorption of carbohydrate but not of triacylglycerol in healthy volunteers. Am. J. Clin. Nutr. 84(3): 551-555. DOI: 10.1093/ajen/84.3.551

Zhu J, Chen C, Zhang B, Huang Q (2020) The inhibitory effects of flavonoids on $\alpha$-amylase and $\alpha$-glucosidase. Critical Reviews in Food Science and Nutrition 60(4): 695-708, DOI: 10.1080/10408398.2018.1548428

Zhu W, Jia Q, Wang Y et al. (2012) The anthocyanin cyanidin-3-O- $\beta$-glucoside, a flavonoid, increases hepatic glutathione synthesis and protects hepatocytes against reactive oxygen species during hyperglycemia: Involvement of a cAMP-PKA-dependent signaling pathway. Free Radic. Biol. Med. 52(2): 314-327. DOI: 10.1016/j.freeradbiomed.2011.10.483 